\title{
One-way coupling of an integrated assessment model and a water resources model: evaluation and implications of future changes over the US Midwest
}

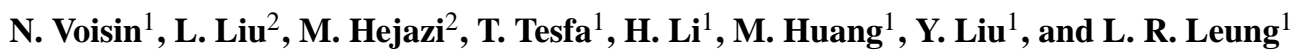 \\ ${ }^{1}$ Pacific Northwest National Laboratory, Richland, WA, USA \\ ${ }^{2}$ Joint Global Change Research Institute, Pacific Northwest National Laboratory, College Park, MD, USA \\ Correspondence to: N. Voisin (nathalie.voisin@ pnnl.gov)
}

Received: 2 April 2013 - Published in Hydrol. Earth Syst. Sci. Discuss.: 22 May 2013

Revised: 14 September 2013 - Accepted: 10 October 2013 - Published: 18 November 2013

\begin{abstract}
An integrated model is being developed to advance our understanding of the interactions between human activities, terrestrial system and water cycle, and to evaluate how system interactions will be affected by a changing climate at the regional scale. As a first step towards that goal, a global integrated assessment model, which includes a water-demand model driven by socioeconomics at regional and global scales, is coupled in a one-way fashion with a land surface hydrology-routing-water resources management model. To reconcile the scale differences between the models, a spatial and temporal disaggregation approach is developed to downscale the annual regional water demand simulations into a daily time step and subbasin representation. The model demonstrates reasonable ability to represent the historical flow regulation and water supply over the US Midwest (Missouri, Upper Mississippi, and Ohio river basins). Implications for future flow regulation, water supply, and supply deficit are investigated using climate change projections with the $\mathrm{B} 1$ and $\mathrm{A} 2$ emission scenarios, which affect both natural flow and water demand. Although natural flow is projected to increase under climate change in both the B1 and A2 scenarios, there is larger uncertainty in the changes of the regulated flow. Over the Ohio and Upper Mississippi river basins, changes in flow regulation are driven by the change in natural flow due to the limited storage capacity. However, both changes in flow and demand have effects on the Missouri River Basin summer regulated flow. Changes in demand are driven by socioeconomic factors, energy and food demands, global markets and prices with rainfed crop demand handled directly by the land surface modeling com-
\end{abstract}

ponent. Even though most of the changes in supply deficit (unmet demand) and the actual supply (met demand) are driven primarily by the change in natural flow over the entire region, the integrated framework shows that supply deficit over the Missouri River Basin sees an increasing sensitivity to changes in demand in future periods. It further shows that the supply deficit is six times as sensitive as the actual supply to changes in flow and demand. A spatial analysis of the supply deficit demonstrates vulnerabilities of urban areas located along mainstream with limited storage.

\section{Introduction}

Water is essential for a wide range of human activities, including energy production and agricultural systems. Observational and modeling studies have suggested an accelerated hydrological cycle in a warmer climate (Held and Soden, 2006) and amplification of precipitation extremes (Allan and Soden, 2008). Changes in water supply can have profound impacts on energy production and land use. How human systems respond to climate change can provide feedbacks on the climate and water cycle. Therefore, predicting climate change requires modeling systems that represent the fully integrated natural and human components of the water cycle. This is a significant scientific challenge because human components are more local and regional in scales while the natural systems exhibit variability over a wider range of spatial scales. Hence, representing the integrated water cycle must reconcile the scale differences. In addition, many of the 
processes governing the interactions in the coupled humanearth system are not fully understood.

Global integrated models are being developed (Pokhrel et al., 2012; Biemans et al., 2011; Döll et al., 2009; Haddeland et al., 2006) to advance our understanding of the interactions between human activities, the terrestrial water cycle, and how they will be affected by the changing climate at regional and global scales. In those models, water demands are represented using physically-based models, usually related to irrigation demands simulated by crop models, while water demands from other sectors such as energy are ignored or prescribed. At regional scales, assessments of climate change impacts on water resources have been performed using hydrologic models driven by climate change scenarios, with or without water management and usually assuming no change in land use (e.g., Backlund et al., 2008). Recently some analyses have been performed combining the effect of land use change and climate change on natural water resources, with land use primarily driven by population and urbanization while changes in agriculture or effects of reservoir operations are not considered (Cuo et al., 2011; Mishra et al., 2010). Although these studies have provided important insights on future changes in water resources driven by climate change and/or land use change, with or without adaptation by water management, none have fully reconciled the socioeconomic, land use, energy, water demand, and climate drivers used to assess the hydrologic impacts and water management options.

This study represents a step towards developing an integrated framework that represents both human and natural system drivers of water cycle and climate changes with the goal towards a fully coupled modeling system that reconciles the hydrology and water management simulated at local/regional scales with water demand and land use driven by socioeconomics at regional/global scales. A oneway coupling is presented to first address the scaling challenge and evaluate the skill of the models. We implement a subbasin configuration of a land surface model to simulate available water (runoff and baseflow) coupled with a river routing model (Model for Scale Adaptive River Transport or MOSART) and a water resources management model (WM), and a global integrated assessment model (IAM). The adopted IAM simulates water demand by sector (irrigation, domestic, industrial, etc.) driven by socioeconomic factors, technologically detailed energy and food demands, and climate mitigation targets in a fully integrated system. However, the IAM does not yet account for climate change impacts on water demands. The modeling of water demands is focused mainly on the implications of climate mitigation policies, socioeconomic drivers (population, income, food and energy demands, etc.), and technological change implications. In this study, thus, climate change impacts are primarily captured through changes in water availability, and consequently in water supply deficits.
The linkage of the Global Change Assessment Model (GCAM) and a subbasin implementation of the Community Land Model (SCLM) facilitates the propagation of human decisions pertaining to water demand per sector and technology from the assessment decision framework to SCLM at the appropriate temporal and spatial scales. Although this coupling is still one way (i.e., no feedback is considered from SCLM-MOSART-WM to GCAM), it constitutes a key step toward establishing a consistent, integrated framework of water modeling that is portable, consistent with global modeling and analyses, and provides significant improvements and insights into the interaction of human decisions and climate changes at regional scales. The proposed oneway coupling of an IAM (i.e., GCAM) and an earth system model or ESM (i.e., SCLM) aims at improving the representation of the interaction pathways that govern the evolution of the hydrologic components that are integral to the energy, water and land components of the Earth system, in the context of changing climate. By accounting for water demands as a function of the socioeconomic factors, energy and food demands, global markets and prices, IAMs provide an economic platform to meaningfully represent human activities and their roles in affecting the water cycle.

The paper describes the methodology to couple the water demand component of a global integrated assessment model to the terrestrial system component, consisting of a land surface model, a river routing model and a water resources management model of an earth system model (ESM). The integrated models are driven by global simulations of current and future climates and are evaluated over the historical period using observations. Implications of combined changes in climate and human factors (socioeconomics, energy and food demands, and climate mitigation targets represented by the global integrated assessment model) on future water resources are assessed from simulations by the integrated models for future time periods. This study brings global modeling efforts on climate change impacts and related mitigation activities to the regional scale, with a focus on modeling and analysis over the US Midwest with strong interactions among water, energy, and land use.

The next section presents the domain and the models. Section 3 describes the approach to couple the demand model to the terrestrial system model. Section 4 evaluates the integrated model over the historical period, assesses implications for the future and identifies the drivers of change.

\section{Domain, models and datasets}

\subsection{Domain}

The US Midwest region is chosen for the first application of the integrated models. The domain includes the Missouri, Upper Mississippi and Ohio River basins (Fig. 1), hereinafter denoted as the Midwest Region. The crop in the region is 


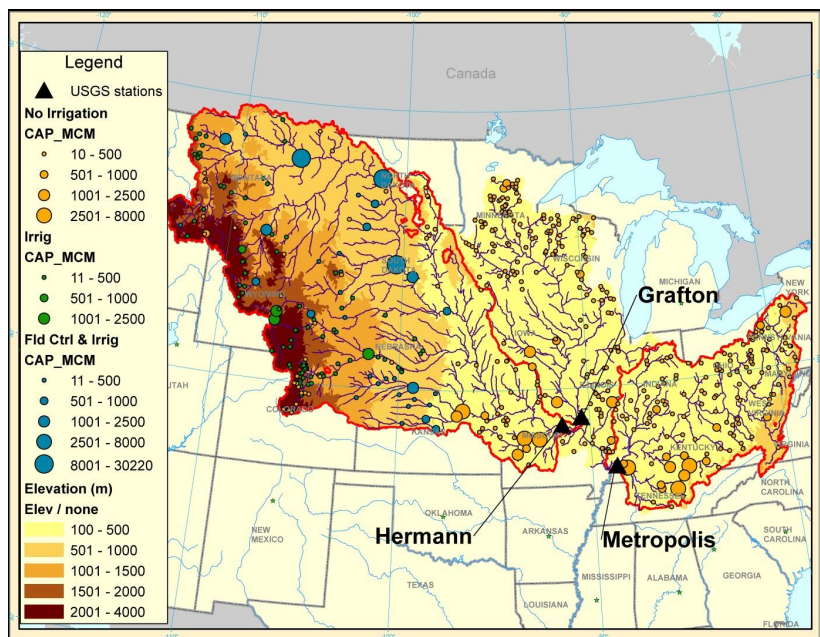

Fig. 1. GRanD reservoir database by type of operating rules over the three regions of the US Midwest targeted in this study: Missouri, Upper Mississippi and Ohio. Flow is validated at the outlet of the three regions: Missouri at Hermann (06934500), Upper Mississippi at Grafton (05587450) and Ohio at Metropolis (03611500).

mostly rainfed over the Upper Mississippi, Ohio and Northern Missouri river basins. Natural flow has been shown, at least over the Upper Mississippi river basin (Frans et al., 2013; Mishra et al., 2010), to be more sensitive to climate change than to land use change. However, this region represents many crosscutting issues on climate, energy, land use, and water, including water quality. For example, the US Midwest is a major area for bioenergy resource, representing potential conflicts between food and fuel. In addition, the US Midwest is of primary importance for regional and international water markets, and hence represents an interesting test case for our modeling framework that aims to model global water transfer in the future.

There are 476 geo-referenced reservoirs over the region (GRanD database, Lehner et al., 2008) and all of them are modeled in the study (Fig. 1). Despite their small capacities, Lehner et al. (2011) demonstrated their importance in the regulation of the flow at larger scales. Also, keeping all reservoirs in the model allows us to test the model for potential applications across multiple spatial scales in the future.

The Missouri River has its headwater in the Rockies, which provides a late spring water storage for the agriculture rich region. The Missouri River Basin has 194 reservoirs according to the GRanD database (Lehner et al., 2008); out of those reservoirs, 125 are used for irrigation and not flood control, 29 are used jointly for both irrigation and flood control, and the remaining 40 reservoirs are used for other uses like hydropower and supply (Fig. 1). The Upper Missouri is used mostly for combined flood control and irrigation, the Platte River and the upper Kansas River are used for irrigation but not flood control, while the downstream Kansas and Osage rivers are used mostly for flood control and not irriga- tion. The most downstream station along the Missouri River before its confluence with the Mississippi River is Hermann, MO, which drains $1371010 \mathrm{~km}^{2}$ of semi-arid lands.

The Ohio River Basin lies in the eastern part of the domain with its headwater in the Appalachians and is the main tributary in volume to the Mississippi River (Fig. 1). The Ohio River basin has 131 reservoirs according to the GRanD database; none are used for irrigation, 71 are used in part for flood control. Other usages include navigation, recreation, hydropower or water supply as this is a heavily populated region ( 25 million, $8 \%$ of the US population; Ohio River Valley Sanitation Commission). The downstream station is Metropolis, IL, which drains $525727 \mathrm{~km}^{2}$ of humid subtropical and humid continental climate areas.

The Upper Mississippi River has its headwaters above Minneapolis. The basin includes 220 reservoirs with none for irrigation and 25 for flood control. Above Minneapolis, reservoirs are mostly for hydropower and recreation while downstream reservoirs are mostly for navigation; 112 of them have a reservoir capacity of less than 500 million cubic meters. The downstream station prior to the confluence with the Missouri is Grafton, IL (443 $\left.475 \mathrm{~km}^{2}\right)$.

Reservoir regulation for navigation is a priority in the Ohio River basin, the Upper Mississippi River basin, and along the main stem of the Missouri River. In our generic water resources model detailed below, operating rules differ for (i) irrigation only, (ii) combined irrigation and flood control, and (iii) other usages. The operating rule for other usages is consistent with navigation, with the aim to have a uniform flow throughout the year. However, over the main stem of the Missouri River the priority is given to irrigation, which prescribes seasonality in the monthly releases. Control for navigation requires joint operations between reservoirs of different storage capacity, with coordination for withdrawals over multiple timescales, which are not represented here. However, at a monthly timescale, the effect of reservoir regulation on streamflow matches reasonably well the observed regulated flow, as shown in Voisin et al. (2013) and in the next sections.

\subsection{Models and datasets}

Figure 2 presents the schematic of the modeling approach. A water resources management model (Voisin et al., 2013) has been developed and coupled to a routing model called Model for Scale Adaptive River Transport (MOSART) (Li et al., 2013a). The coupled model, MOSART-WM, takes as input the daily runoff and baseflow generated by a land surface hydrology model, a subbasin implementation of the Community Land Model (SCLM) (Lawrence et al., 2011; Li et al., 2011), and the total consumptive water demand provided by a water demand model of the Global Change Assessment Model (GCAM) (Hejazi et al., 2013a; Wise et al., 2009; Kim et al., 2006; Clarke et al., 2007a, b; Brenkert et al., 2003). The land surface scheme SCLM is forced by meteorological data 


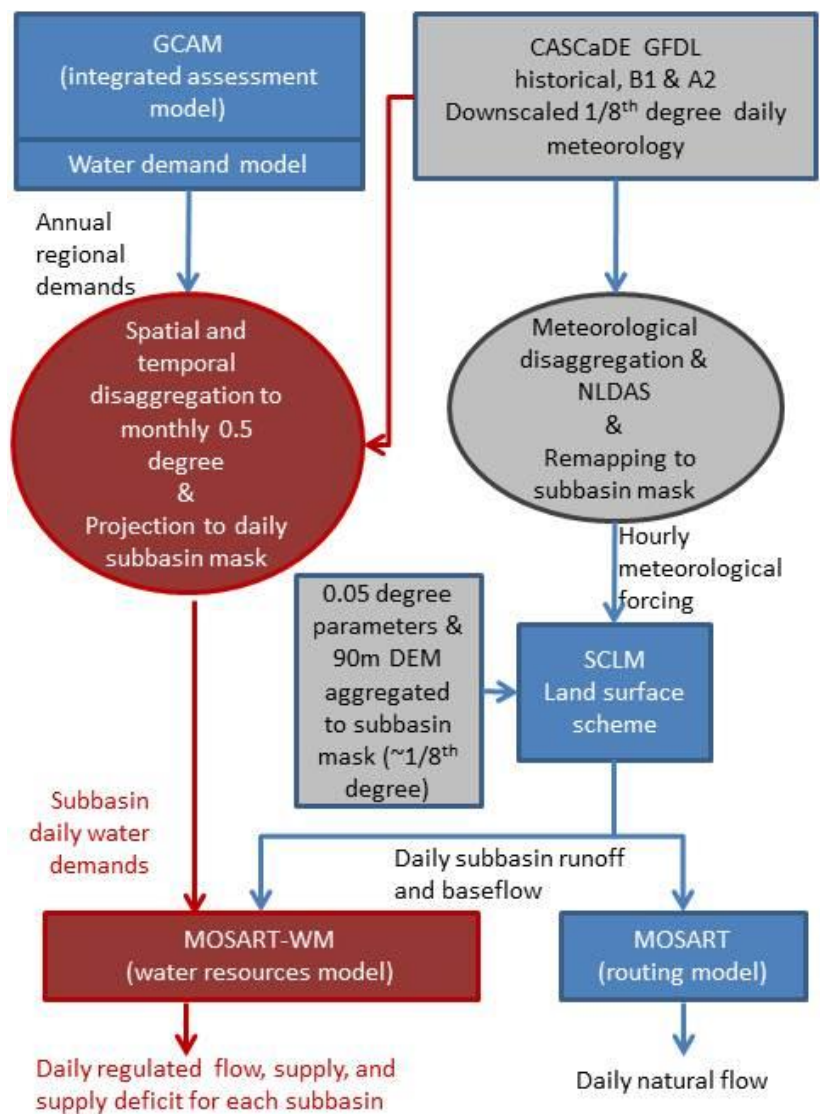

Fig. 2. Schematic of the system. The paper describes and evaluates the coupling of the water demand model with the water resources model (red). Publicly available datasets processed for the experiments are in grey. Models are in blue.

statistically downscaled from global climate model simulations for the historical and future periods (Fig. 2). The next sections present details about the different models.

\subsubsection{A subbasin-based framework for land surface hydrologic modeling}

In this study, we applied the subbasin-based version of Community Land Model version 4 (hereinafter denoted as SCLM, Li et al., 2013b; Tesfa et al., 2013), for hydrologic simulations over the study region. CLM is the land component within the Community Earth System Model (CESM) (formerly known as Community Climate System Model) (CCSM) (Lawrence et al., 2011). CLM is also the land surface component in a regional earth system model based on the Weather Research and Forecasting (WRF) model (Ke et al., 2012; Kraucunas et al., 2013; Leung et al., 2006). The capability of CLM4 for hydrologic simulations has recently been assessed at small watershed to larger basin scales (Huang et al., 2013; Li et al., 2011, 2013b; Tesfa et al., 2013). CLM simulates the full energy and water balances for a mosaic of rainfed vegetation classes, including crop.
CLM provides the runoff and baseflow for the water management model. In the subbasin-based framework, land surface hydrologic processes such as water and energy transfers between the land surface and the atmosphere, as well runoff generation, are represented by treating each subbasin as a pseudo-grid cell without significantly modifying the existing CLM modeling structure. Subbasin boundaries within the study domain were delineated using ArcSWAT (Neitsch et al., 2005). The study area was delineated into 18681 subbasins with $\sim 120 \mathrm{~km}^{2}$ average size, equivalent to $1 / 8$ th degree grid cells, making it comparable to the North American Land Data Assimilation System (NLDAS2) (Cosgrove et al., 2003). Soil, vegetation and land cover characteristics of each subbasin $(\sim 1 / 8$ th degree $)$ in the study domain were derived from the high resolution $0.05^{\circ}$ CLM4 input dataset developed by Ke et al. (2012), by overlaying the watershed boundaries with the data layers and aggregating to each basin using an area weighted average algorithm, following Li et al. (2013b). Hydrologic parameters relevant to topography were obtained by processing the $90 \mathrm{~m}$ resolution DEMs from HydroSHEDS (Lehner et al., 2008), consistent with the SCLM model setup in Li et al. (2011, 2013b), Huang et al. (2013) and Tesfa et al. (2013). SCLM was spun up using hourly forcing described below for the historical period 1976-1999 for 10 cycles (300 yr total), until all the state variables reached equilibrium.

\subsubsection{Atmospheric forcing data}

Daily precipitation and temperature at $1 / 8$ th degree resolution were retrieved from the Computational Assessments of Scenarios of Change for the Delta Ecosystem (CASCaDE) dataset (http://cascade.wr.usgs.gov). The CASCaDE dataset was developed by applying the constructed analog statistical downscaling method (Hidalgo et al., 2008) to the historical and future climate simulations generated by the Geophysical Fluid Dynamics Laboratory Coupled Climate Model (GFDL CM2.1) (Delworth et al., 2006) for the Coupled Model Intercomparison Project (CMIP3). The future climate simulations follow the Special Report for Emission Scenarios SRES B1 and A2 emission scenarios. The 1/8th degree downscaled daily precipitation and temperature time series from 19752100 were further processed with the forcing disaggregator of the Variable Infiltration Capacity model (VIC) (Liang et al., 1994) (www.hydro.washington.edu/Lettenmaier/Models/ VIC/Documentation/VICDisagg.shtml) to generate hourly precipitation, temperature, and shortwave radiative fluxes using the MTCLIM 4.2 algorithm (Thornton and Running, 1999; Thornton et al., 2000); incoming longwave radiation fluxes (the Tennessee Valley Authority algorithm, TVA, 1972); and specific humidity (Kimball et al., 1997) required by SCLM. Wind speed and surface pressure data were obtained from the North American Land Data Assimilation System (NLDAS) (Mitchell et al., 2004). The hourly $1 / 8$ th degree meteorological data were then projected to the 
subbasin boundaries discussed earlier using an area average algorithm as input into SCLM (Fig. 2). The GFDL-B1 and GFDL-A2 scenarios portray the B1 and A2 emissions scenarios (optimistic and pessimistic, respectively) as modeled by the GFDL CM2.1 model, which has climate sensitivity in the medium range among the IPCC AR4 models. The B1 emission scenario corresponds to the lowest increase in surface temperature among the different greenhouse gas emission scenarios. Economically, it focuses on global environmental sustainability. The A2 scenario concentrates on regional economic development and is one of the scenarios with the largest temperature increase (IPCC, 2007). Although the atmospheric forcings used in SCLM-MOSART-WM are consistent with the climate scenarios in GCAM with regard to the total radiative forcings, GCAM does not explicitly use any gridded climate data as input. The CASCaDE data are simply used to guide the temporal downscaling in a postprocessing step of the GCAM simulated water demand from annual to daily scale, as will be discussed in Sect. 3.2 (Fig. 2).

\subsubsection{The water resources management model (MOSART-WM)}

The water resources model (WM, Voisin et al., 2013) relies on generic operating rules adjusted independently for each reservoir; monthly release targets are based on the longterm mean monthly inflow, the long-term mean monthly demand associated to each reservoir, and reservoir characteristics (storage and uses). Initial work by Hanasaki et al. (2006) and Biemans et al. (2011) included two types of rules in particular: (i) monthly varying releases based on water demand, hydroclimatic characteristics and storage capacity for reservoirs used for irrigation, or (ii) for all other uses release of mean annual flow adjusted for monthly demand anomalies (flood control, navigation, conservation, recreation). Voisin et al. (2013) updated the release targets and complemented them with storage targets in order to improve joint flood control and irrigation uses. The WM includes (i) a local extraction module that extracts from the local surface water and river channel to provide in priority for the local demand; (ii) a reservoir module that simulates the reservoir storage, regulates the releases and provides supply to each grid cell in need; and (iii) an interdependency database that assigns to each reservoir a list of subbasins that can receive water from that reservoir and controls the weighted distribution of the supply, and similarly assigns to each subbasin the list of reservoirs it can request water from and controls the weighted distribution of the demand to each reservoir (see Voisin et al., 2013 for further details). The seasonal patterns of the operating rules is monthly, and there is interannual variability of those monthly preset releases based on the initial storage at the start of the irrigation season. However, the extraction is performed at the time step of the run - presently daily. Releases adjustment for spilling, minimum environmental flow and drying reservoirs are also made at the time step of the run. The WM is coupled to the Model for Scale Adaptive River Routing (MOSART) (Li et al., 2013a) river routing model. In this experiment, MOSART-WM is run independently of the land surface model (SCLM) described above. The return flow is, however, implicitly simulated as we only extract the GCAM consumptive use rather than the withdrawals. The dynamic coupling is an area of research and in particular we investigate the effect that the uncertainties in the localization of the extraction and the redistribution of water will have on the overall modeling. Input for MOSARTWM includes daily surface and subsurface runoff, and daily total water consumptive demand, not withdrawals, provided by the water demand model described below. However, an estimate of withdrawals is used for the optimal calibration of the release targets, as explained in Voisin et al. (2013).

\subsubsection{GCAM}

The global change assessment model (GCAM) is a dynamicrecursive model that encompasses technologically-detailed representations of human and natural systems and their interactions (Wise et al., 2009; Kim et al., 2006; Clarke et al., 2007a, b; Brenkert et al., 2003). The model includes representations of the global economy, the energy system, agriculture and land use, and climate. It models global trade in fossil energy and agricultural products and solves for prices of all energy, agricultural, and forest productivities to balance off demands and supplies (Calvin et al., 2013). This is useful, even though the focus of the work is regional in nature (e.g., US Midwest), because global decisions associated with adhering to the adopted B1 and A2 climate mitigation scenarios have regional implications (e.g., bioenergy production in the Midwest Region).

Recently, Hejazi et al. (2013a, b, c) explicitly incorporated sectoral water demand modules in GCAM to estimate the amount of freshwater demanded on an annual basis. The water demand modules account for the annual amount of water demanded by a set of individual sectors, namely irrigation (Chaturvedi et al., 2013); electricity generation (Davies et al., 2013; Kyle et al., 2013); livestock, domestic purposes (Hejazi et al., 2013d); primary energy production; and manufacturing (Hejazi et al., 2013a). GCAM tracks water withdrawals and consumptive use by region (14 geopolitical regions or 151 agro-ecological zones - Monfreda et al., 2009); by sector (e.g., irrigation, electricity, etc.) and subsectors (e.g., fuel type, crop type, etc.); and by technology (e.g., cooling technologies: once-through, recirculating, cooling ponds, and dry cooling). That information is passed onto the water resources model as the demanded amount of consumptive water use by sector. Note, however, that GCAM's water demand estimates are not constrained by the amount of water availability in a basin. When considering river and reservoir routing and human activities within the runoff generation modeling framework plus the seasonality of water availability and existing reservoir storage capacity, not to 


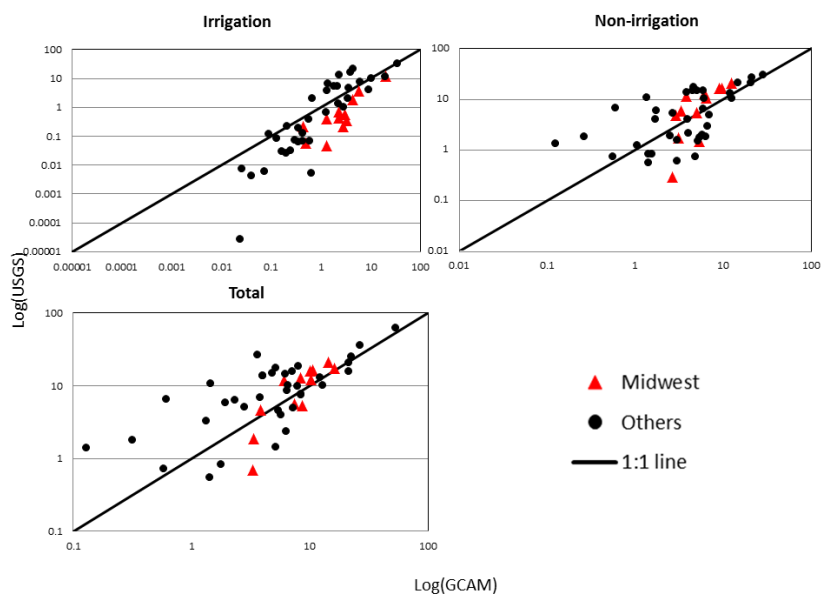

Fig. 3. Comparison of GCAM water withdrawal values in year 2005 to USGS values (log-log scale) by states of the United States, and for the Midwestern states.

mention the modeling uncertainties and scale differences between GCAM and SCLM, the suggested demand by GCAM might end up being infeasible when integrated with SCLMMOSART-WM. In this research, we track the amount of supply deficit (i.e., unmet consumptive water demands) to provide insights on requirements for future implementation of a two-way coupled framework in which unmet consumptive water demands determined by SCLM-MOSART-WM will be used to constrain the GCAM water demand. More details about the water demand methodology in GCAM can be found in Hejazi et al., 2013a).

\section{Coupling of the water demand and water management models}

A one-way coupling between GCAM and SCLM-MOSARTWM is the focus of this paper, where GCAM provides the water demand and SCLM-MOSART-WM computes the water availability and estimates the actual water supply. There is, however, a mismatch in scale both spatially and temporally among the models. GCAM is solved on a $5 \mathrm{yr}$ time step and operates at the regional scale (14 geopolitical regions and 151 agro-ecological zones (AEZs)), which are much coarser than what is required by SCLM-MOSART-WM. The temporal and spatial disaggregations to the subbasin mask and daily resolution of MOSART-WM need to represent spatiotemporal variations of use over the basin. This has implications for the locally available water supply and affects the WM as operating rules of each reservoir are a function of the monthly climatology and magnitude of the demand associated to each reservoir. Disaggregation affects the distribution of water supply to the different subbasins. Thus, to facilitate the proposed coupling, both spatial and temporal downscaling steps were employed, as described next. Note that due
Table 1. Correlation coefficients between GCAM and USGS based on state-level water demand estimates by sector; correlation values in parenthesis are based on the Miwestern states only.

\begin{tabular}{lll|l}
\hline \multirow{2}{*}{ Water demand } & \multicolumn{2}{c|}{1990} & 2005 \\
\cline { 2 - 4 } sectors & Consumption & Withdrawal & Withdrawal* \\
\hline Irrigation & $0.86(0.80)$ & $0.75(0.91)$ & $0.77(0.99)$ \\
Non-irrigation & $0.78(0.77)$ & $0.58(0.93)$ & $0.80(0.87)$ \\
\hline Total & $0.84(0.80)$ & $0.77(0.57)$ & $0.87(0.87)$ \\
\hline
\end{tabular}

* USGS does not provide consumptive water use data for 2005.

to the lack of available tools to downscale land use from the 151-AEZ scale in GCAM to the grid/subbasin scale, SCLMMOSART-WM presently uses the same land use in the future conditions as defined by the current conditions. Reconciliation of land use between the global and regional models is an ongoing research focus for future improvement of the modeling framework.

\subsection{Spatial downscaling}

We adopted the downscaling methodology of Hejazi et al. (2013b) to downscale the individual sectoral demands (irrigation, livestock, municipal, electricity generation, primary energy, and manufacturing water demands) from regional scale (AEZ and GCAM regional scale) to the grid scale $\left(0.5^{\circ} \times 0.5^{\circ}\right)$, and subsequently to the subbasin scale (Fig. 2). In a nutshell, the downscaling algorithms employ proxy information such as population and areas equipped with irrigation information to map water demands to a finer spatial scale of $0.5^{\circ}$. To assess the accuracy of GCAM in combination with the downscaling algorithms in estimating water demands at the regional scale, the spatially downscaled annual sectoral water demands from GCAM are compared against the state-level USGS inventory for the years 1990 and 2005. The six sectors of water demand are sorted into irrigation and non-irrigation (electricity + domestic + mining + livestock + manufacturing) water demands for the purpose of simplification. The total water withdrawals and consumptive use produced by GCAM show a good agreement with USGS values on the state level (Fig. 3). The statistics of the results are shown in Table 1.

\subsection{Temporal downscaling}

GCAM estimates annual demands every five years (GCAM is run with a $5 \mathrm{yr}$ time interval), which need to be temporally disaggregated to daily scale for input into MOSARTWM. The temporal downscaling is performed independently for each water use sector in several steps: first a continuous annual time series of water demands is obtained by linearly interpolating between the $5 \mathrm{yr}$ intervals. Then the annual values are downscaled to monthly through a suite of 
techniques as described below; and, finally, the monthly demands are downscaled to daily using a uniform distribution. This section presents the disaggregation to the monthly timescale. Wada et al. (2011) devised a set of simple methods to map non-irrigation sectors from annual to monthly time step. We adopted their approaches for domestic, mining, livestock and manufacturing, extended the electricity generation technique, and simplified the irrigation one. Each of the steps is described next with validation results.

\subsubsection{Irrigation}

Unlike the work of Wada et al. (2011) who used a crop growth model to estimate monthly irrigation water requirements, crop water requirements in GCAM are computed using a simplified methodology that utilizes estimated coefficients of water requirement per crop type and AEZ from crop growth models to efficiently compute irrigation water on an annual basis (see Chaturvedi et al., 2013). This reduced form is essential to the computational feasibility of iterating food demands and prices hundreds of iterations in each GCAM time period without resorting to running a crop growth model that many times. Also, adopting the use of a gridded physically-based crop growth model would require downscaling the evolution of land use (e.g., cropland expansion) in GCAM for future time periods, a capability that is not yet available and requires future research. GCAM estimates annual irrigation demands every five years (GCAM is run with a $5 \mathrm{yr}$ time interval). Chaturvedi et al. (2013) provide a detailed comparison to the other literature estimates and statistics on irrigation estimates at the regional scale; see Chaturvedi et al. (2013), Hejazi et al. (2013a, b) for further details. Figure 3 shows a comparison of the estimated total irrigation against USGS estimates for water withdrawals at the state level in year 2005. The next step is to temporally downscale GCAM results of irrigation water demand to monthly time series.

The monthly profile for downscaling GCAM irrigation water demand from annual to monthly was obtained from Siebert and Döll (2008) by using irrigation results from the Global Crop Water Model (GCWM). GCWM provided global gridded monthly irrigation water requirements for 26 crop types, which were mapped to the twelve GCAM crop categories to estimate the crop and region specific monthly distribution of irrigation. This enabled us to construct irrigation water use monthly profiles for each of the AEZ regions in the US (Fig. 4a). Following the work of Hanasaki et al. (2013a, b), we applied the same monthly profile for irrigation water withdrawal and consumption. Therefore, irrigation water withdrawal and consumption from GCAM were downscaled from annual to monthly time step by applying the ratios calculated from the monthly profiles distinguished by AEZ (Eq. 1).

$$
W_{i j}=W_{j} \times \text { Ratio }_{\mathrm{AEZ}} \mathrm{ij}_{\mathrm{j}}
$$

where $W_{i}$ indicates irrigation water demand for the month of $i$ in year $j$, and $W_{j}$ indicates annual irrigation water demand.

\subsubsection{Electricity}

In this study, the temporal downscaling of electricity generating water demands in the US was built on the basis of electricity use fluctuations within a year. We assume that the amount of water used for generating electricity in a particular month is proportional to the amount of electricity generated in each month. In GCAM, electricity generation is consumed by three main sectors: industry, transportation, and building. Industry and transportation sectors are assumed to consume equal shares of electricity within a year (i.e., uniform distributions). A simple algorithm is developed to reflect the seasonal fluctuations of electricity use in the building sector based on the concepts of heating degree days (HDD) and cooling degree days (CDD). HDD and CDD are measurements designed to reflect the demand for energy needed to heat/cool a building. It is derived from measurements of outside air temperature.

About $20 \%$ of the total electricity used in buildings in the US is used for heating (5\%) and cooling (15\%) purposes; the remaining $80 \%$ is used by other home utilities. These values are taken directly from GCAM. In this study, only the heating and cooling electricity shares are assumed sensitive to the climate signal. Equation (2) describes the downscaling methodology of annual building electricity use to monthly scale.

$E_{i j}=E_{j} \times\left(0.05 \frac{\mathrm{HDD}_{i j}}{\sum \mathrm{HDD}_{i j}}+0.15 \frac{\mathrm{CDD}_{i j}}{\sum \mathrm{CDD}_{i j}}+0.8 \times \frac{1}{12}\right)$

where $E_{i j}$ indicates electricity used by building sector for the month of $i$ and year $j, E_{j}$ indicates annual electricity used by building sector, $\mathrm{HDD}_{i j}$ is for heating degree days (Eq. 3) and $\mathrm{CDD}_{i j}$ is for cooling degree days (Eq. 4) in month $i$ and year $j$ :

$$
\mathrm{HDD}_{i j}=\sum_{1}^{n}\left(18-T_{d_{i j}}\right) \forall T_{d_{i j}}<18^{\circ} \mathrm{C}
$$

$$
\mathrm{CDD}_{i j}=\sum_{1}^{n}\left(T_{d_{i j}}-18\right) \forall T_{d_{i j}}>18^{\circ} \mathrm{C},
$$

where $d$ indicates the dth day in ith month in year $j, n$ indicates the number of days in ith month in year $j$, and $T_{d_{i j}}$ is the mean daily temperature in day $d$. Since building sectors consume $74 \%$ of the total electricity generated and other sectors (industry and transportation) consume $26 \%$, the final algorithm for the monthly downscaling is

$$
\begin{aligned}
E_{i j} & =E_{j} \times\left(0.74 \times\left(0.05 \frac{\mathrm{HDD}_{i j}}{\sum \mathrm{HDD}_{i j}}\right.\right. \\
& \left.\left.+0.15 \frac{\mathrm{CDD}_{i j}}{\sum \mathrm{CDD}_{i j}}+0.8 \times \frac{1}{12}\right)+0.26 \times \frac{1}{12}\right),
\end{aligned}
$$



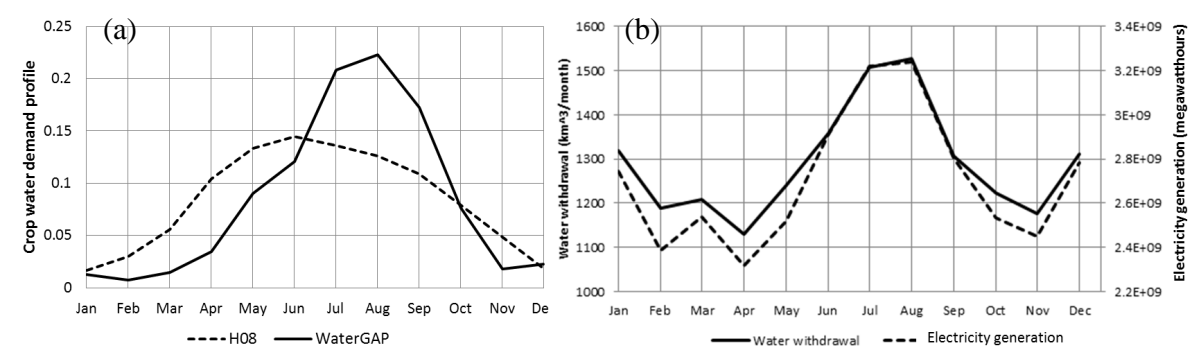

(c)
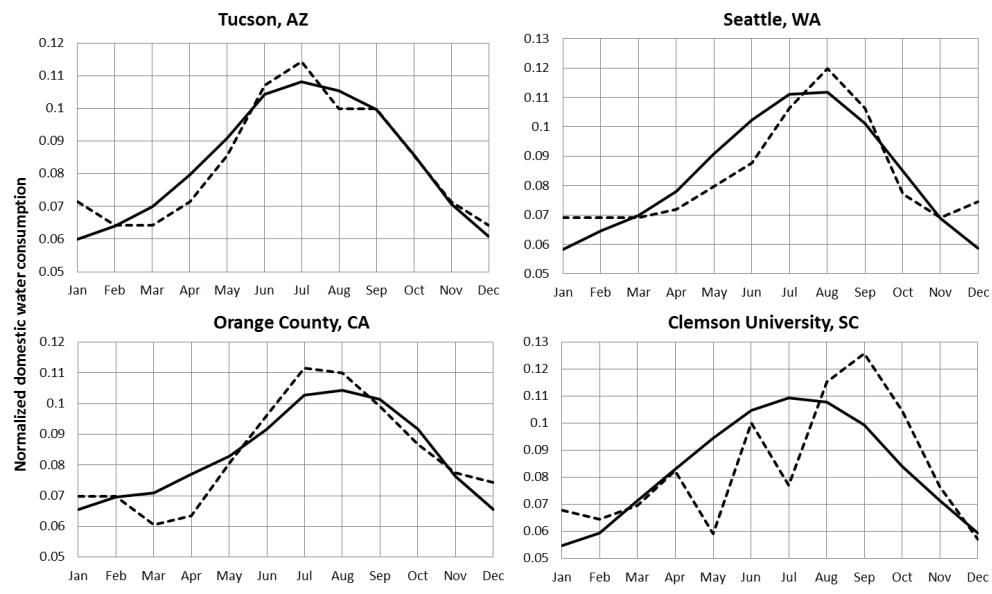

Fig. 4. Temporally downscaling GCAM's annual water demands to monthly profiles: (a) irrigation water demand profiles averaged over all AEZs from two models; (b) US monthly water withdrawal for electricity generation for the year 2005; (c) normalized monthly domestic water consumption for Tucson, AZ, Seattle, WA, Orange County, CA, and Clemson University, SC; the dashed line is calculated based on reported water consumption and the solid line is calculated from 1990 GCAM output using Eq. (7).

where $E_{i j}$ indicates electricity used in month $i$ and year $j$, and $E_{j}$ indicates annual electricity used. The monthly water demand for electricity generation, therefore, is

$$
\begin{aligned}
W_{i j} & =W_{j} \times\left(0.74 \times\left(0.05 \frac{H D D_{i j}}{\sum H D D_{i j}}\right.\right. \\
& \left.\left.+0.15 \frac{C D D_{i j}}{\sum C D D_{i j}}+0.8 \times \frac{1}{12}\right)+0.26 \times \frac{1}{12}\right),
\end{aligned}
$$

where $W_{i j}$ indicates total thermoelectric water demand in month $i$ and year $j$, and $W_{j}$ indicates annual thermoelectric water demand. As shown in Fig. 4b, the total water withdrawal for electricity generation is downscaled to monthly level (using Eq. 6) and compared to the total electricity generation in year 2005. HDD and CDD are calculated from bias corrected and downscaled GFDL temperature historical and future simulations.

\subsubsection{Domestic}

Domestic water demand is temporally downscaled using the algorithm developed by Wada et al. (2011). The equation is

$W_{i j}=\frac{W_{j}}{12}\left[\left(\frac{T_{i j}-T_{\mathrm{avg}_{j}}}{T_{\max _{j}}-T_{\min _{j}}} R\right)+1.0\right]$, where $W_{i j}$ is water demand in month $i$ and year $j, T_{i j}$ is monthly temperature, $T_{\operatorname{avg}_{j}}, T_{\min _{j}}, T_{\max _{j}}$ are average, minimum and maximum temperature over the year, and $R$ is an amplitude (dimensionless), which adjusts the relative difference in domestic water demand between the months with the warmest and the coldest temperatures.

Wada et al. (2011) suggested an $R$ of 0.1 based on their assessments in Spain and Japan. However, this term is found to be closer to around 1.0 in the US, based on four cities that lie within four climate zones (See Fig. 4c).

\subsubsection{Mining, livestock and manufacturing}

For the temporal downscaling of water demand in mining, livestock, and manufacturing sectors, a uniform distribution $(1 / 12)$ is applied following the work of Wada et al. (2011).

The historical monthly downscaled sectoral water demand results are shown in Fig. 5, divided into four categories: irrigation consumption, irrigation withdrawal, non-irrigation consumption and non-irrigation withdrawal. Figure 5a and b show the total annual water demands for the Midwest region, and the monthly time series after applying the temporal downscaling step, respectively. By spatially downscaling demands, a similar time series is generated for each of the subbasins. Water demands in summer are relatively higher than 
in winter for both irrigation and non-irrigation sectors. Future water demands are derived similarly using bias corrected and downscaled GFDL temperatures data.

\section{Evaluation and future implications}

The GCAM demand has been evaluated with respect to the USGS demand showing a close agreement in the previous section. The land surface hydrology model (SCLMMOSART) simulation is evaluated with respect to the historical naturalized observed flow. The water resources management model (GCAM-SCLM-MOSART-WM), in particular the effect of extraction and regulation with respect to the natural system, is evaluated by comparing the observed and simulated differences between the natural and regulated flows. The term supply is usually associated with available water, i.e., flow. The actual supply is the water that is first extracted locally and next from the reservoir releases, according to reservoir operation rules and environmental constraints in order to satisfy the requested demand to that reservoir. The actual supply is a function of the demand and the natural flow; this is the met demand. We refer to supply deficit as the difference between the demand and the actual supply, the unmet demand.

We first evaluate the simulated impact of anthropogenic activities on the simulated historical flow (1984-1999) at the outlet of the three regions of interest: Missouri, upper Mississippi, and Ohio. The impact on flow and the supply deficit as simulated by historical GCAM-SCLM-MOSART-WM are both analyzed with respect to the baseline SCLM-MOSART simulated natural flow. Future water resources, i.e., future regulated flow and water supply, are affected by changes in natural flow (climate driven) and water demands (socioeconomics driven), and also climate change adaptation in the operating rules of the reservoirs (Viers, 2011). However, as a simplification, operating rules based on historical flow and demand are kept unchanged throughout the future simulation (see discussion section). To evaluate the implications of predicted anthropogenic activities on the projected water resources of the US Midwest, we compare the predicted change in natural flow (climate change effect only) and the predicted change in regulated flow (combined climate and demand changes). We isolate the main drivers for the predicted change in actual water supply: changes in flow and/or demand by regions, which differ in their type of demands, storage capacity, and operating rules (Fig. 1).

\subsection{Historical evaluation}

We evaluate the change in the 1984-1999 monthly flow climatology due to the human activities, including regulation and extraction of water over the three regions. We similarly evaluate the water supply deficit. Spun-up SCLM forced with historical statistically downscaled GFDL meteorolog- ical forcing provides the daily surface runoff and baseflow forcing. The routing model MOSART is run as a first step in order to simulate the naturalized flow at the three locations of interest, the baseline scenario. It also provides the longterm mean monthly flow used to update the operating rules. GCAM provides the daily total water consumptive demand to the water resources model MOSART-WM to simulate the regulated flow and water supply. The historical monthly regulated flow and water supply climatologies serve as the reference for evaluating the effect of climate change in the following sections.

Figure 6 shows the mean monthly simulated and observed natural and regulated flow over the three regions, and the relative change in flow due to anthropogenic influence for the historical period only. Figure 7 shows the simulated longterm annual time series of natural and regulated flows at the same locations. Only at Hermann are both the naturalized and regulated flow available. At Metropolis and Grafton, the regulation at the monthly timescale is negligible given the storage capacity over the basin. The downscaled GFDL climate tends to be drier with higher radiative forcing than the forcing from the North American Land Data Assimilation System (NLDAS2) (Cosgrove et al., 2003), which is derived from observed temperature and precipitation data. The biases in the atmospheric forcing lead to an overall underestimation of runoff. The runoff coefficients over the different regions using either the downscaled GFDL or NLDAS as forcing to SCLM are both around 0.17, 0.32, and 0.39 at Hermann, Grafton and Metropolis, respectively. As a reference, the Maurer et al. (2002) hydrological simulations using the calibrated Variable Infiltration Capacity (VIC) hydrology model (Liang et al., 1994) and station based meteorological forcing have runoff coefficients of $0.16,0.21$, and 0.40 at the same locations, although their simulated flow is more in agreement with observations. See the discussion section for more details on the uncertainty in the hydrologic simulations. The right column in Fig. 6 shows the monthly impact of extraction and regulation on the naturalized flow. Table 2 shows the annual effect of river regulation and extraction on the simulated natural flow. Both over the Ohio and the Upper Mississippi river basins the extraction and regulation are minimal at the monthly and annual timescales $(-2 \%$ and $-8 \%$, respectively). Based on the analysis of observed regulated and naturalized flows, the regulation and extraction result in an observed estimate of $16 \%$ loss in annual discharge over the Missouri river basin over the 1984-1999 period. Our higher simulated estimate of $28 \%$ is explained by the fact that (i) we do not take into account groundwater pumping at this time and (ii) the simulated natural flow underestimates the observed naturalized flow. The seasonal effect of extraction and regulation on the natural flow is in agreement with observations but over the October-December low flow period, the change tends to be of opposite effect. Given the simplified generic operating rules, the human activities on the flow are reasonably well-captured by the SCLM-MOSART-WM 

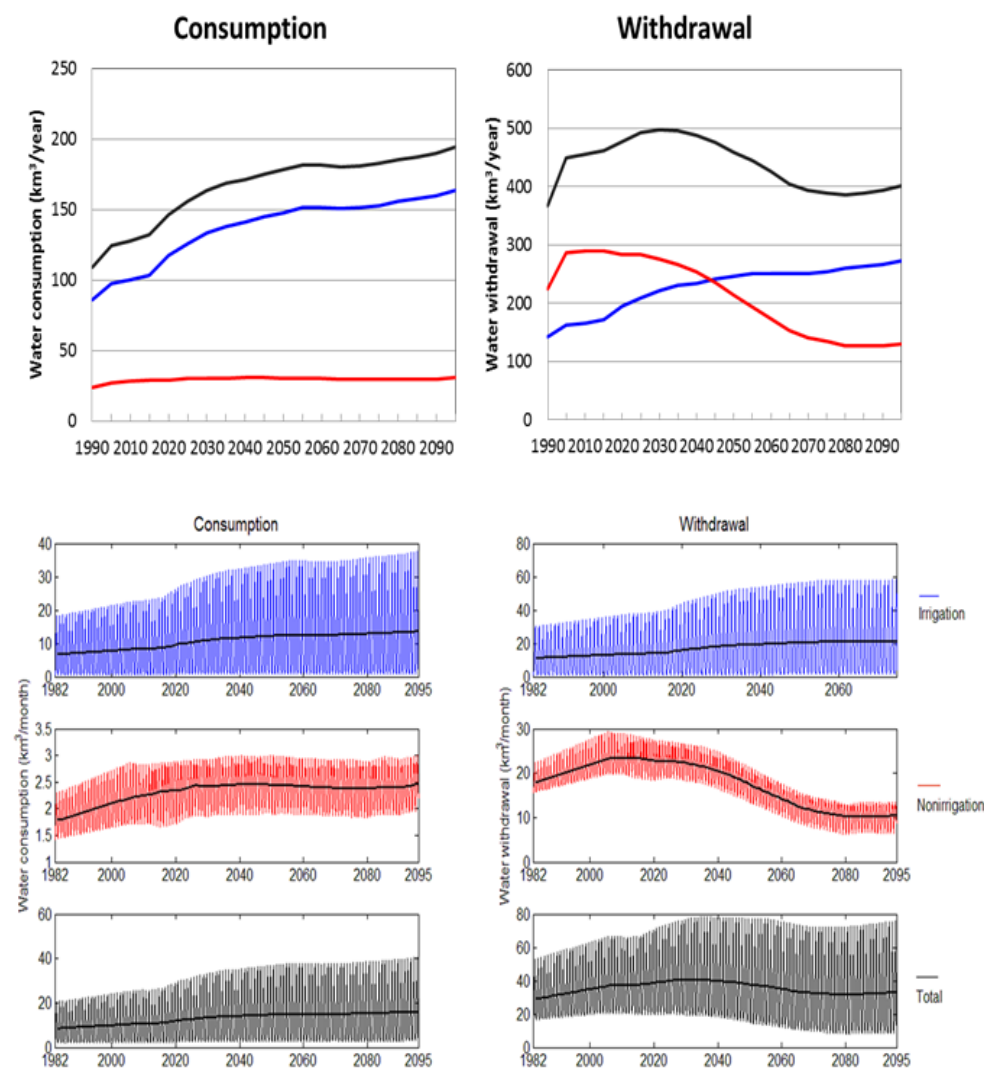

Fig. 5a. (a) Annual water demand by sector from GCAM for the time period 1990-2095 under B1 scenario. (b) Monthly downscaled water demand by sector for the time period 1982-2095 under B1 scenario.
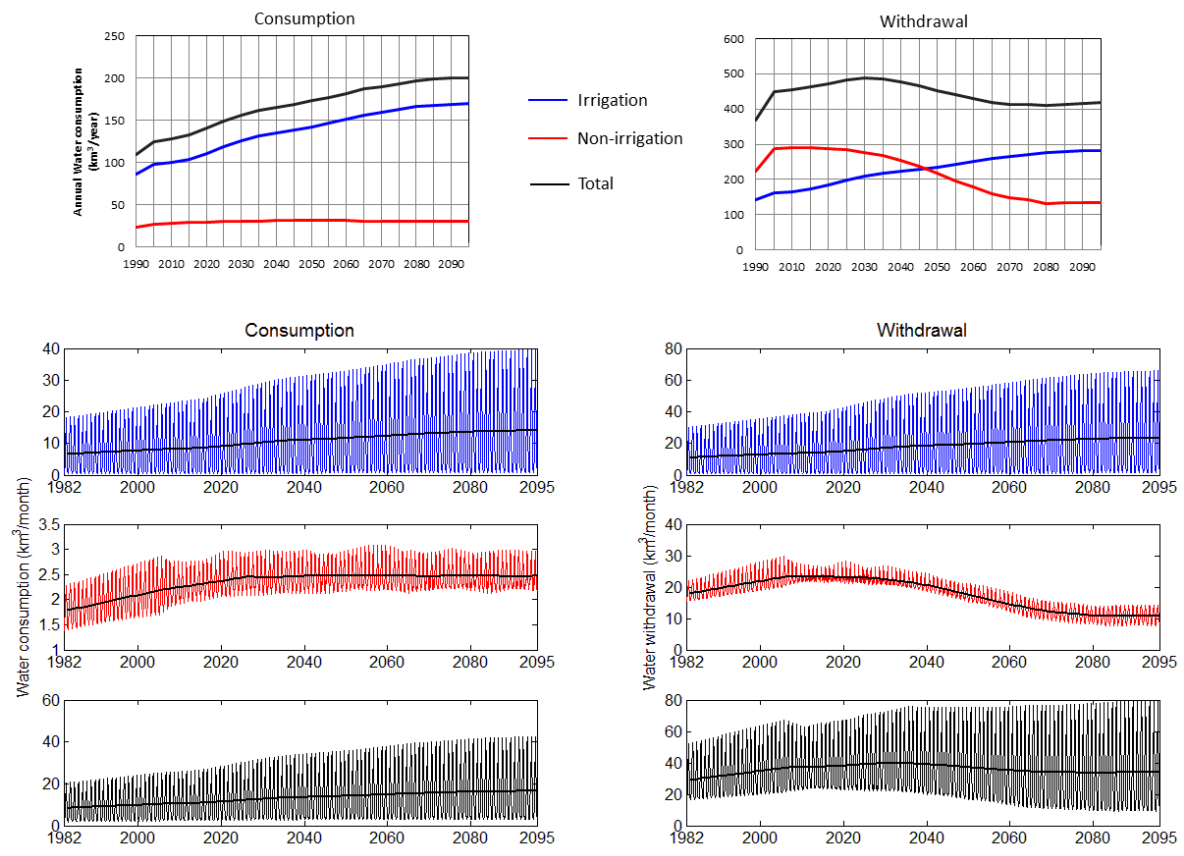

Fig. 5b. (a) Annual water demand by sector from GCAM for the time period 1990-2095 under A2 scenario. (b) Monthly downscaled water demand by sector for the time period 1982-2095 under B2 scenario. 

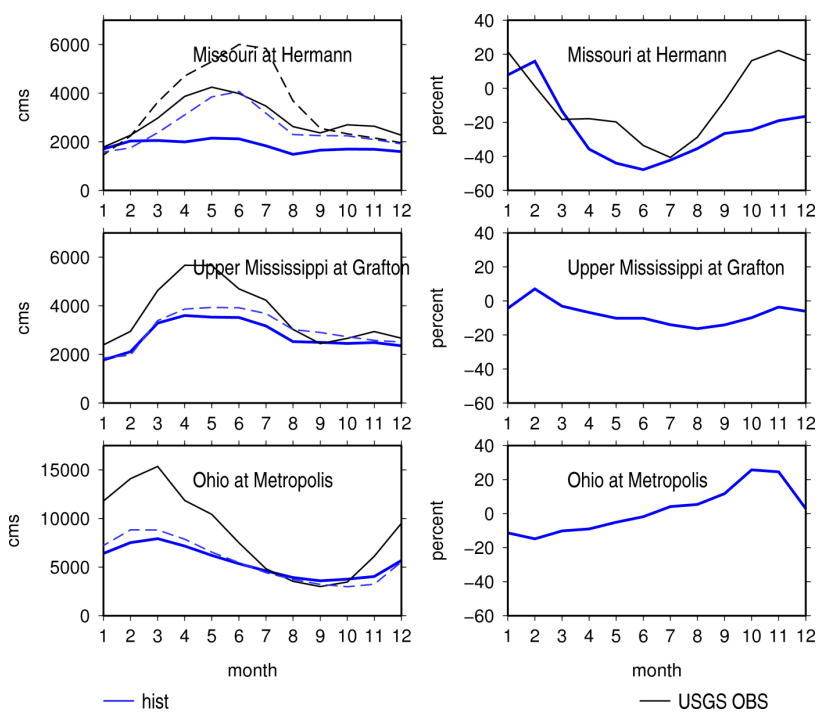

Fig. 6. Simulated natural (dashed) and regulated (solid) flow (left column) and relative change in flow due to regulation (right column) over the three US Midwestern regions: Missouri, Upper Mississippi and Ohio river basins for the historical period 1984-1999.

integrated model forced with GCAM demand and the downscaled GFDL historical climate.

Figure 8 shows the regional average monthly demands and supply deficit for the historical period, and Table 3 shows the historical relative annual water supply deficit. Over the US Midwest the supply deficit is around $3 \%$ and $1.5 \%$ over the Missouri River basin. Since we extract the observed consumptive use, the supply deficit was expected to be very low. Our estimated supply deficit with respect to the observed water use over the historical period likely results from (i) not simulating groundwater pumping at this time and (ii) forcing and modeling errors. The low values of supply deficit denote a reasonable accuracy, i.e., limited uncertainty, in the integrated system modeling chain. As discussed later, the supply deficit is localized in the southwest Missouri River basin where deep groundwater pumping is used and over the urban areas around the Great Lakes, which can also be used as additional freshwater source

\subsection{Future implications}

For evaluating future implications we refer to seasonal and annual relative changes in natural and regulated flows, demand, actual supply and supply deficit with respect to the historical period. We also identify drivers of change using (i) covariances of supply deficit with annual inflow and annual demand over different future periods, and (ii) elasticities with respect to changes in natural flow and changes in demand. The covariances quantify the impact of changes in natural flow and changes in demand on the supply deficit over our simulations. Larger covariances with respect to flow than
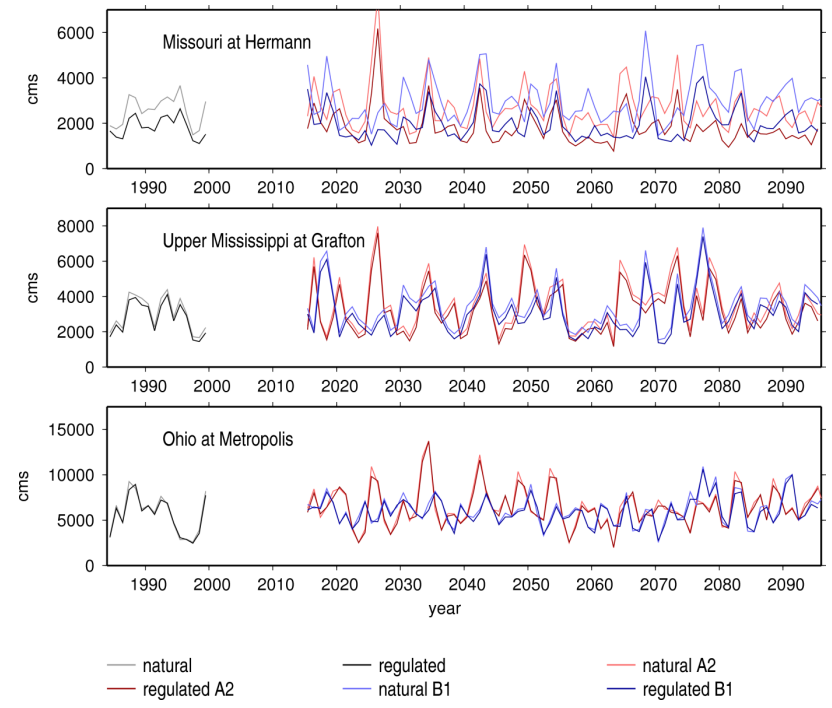

Fig. 7. long-term simulated time series of historical and future (B1) mean annual regulated and natural flow for the three regions.

with respect to demand support that the flow is the primary driving component for changes in supply deficit. The elasticities are the ratios of the relative changes in supply deficit, actual supply or regulated flow, over the relative change in natural flow or demand. Elasticities quantify the sensitivity of the variables to changes in predicted flow and demand and generalize the results on the identification of the drivers of change. Large elasticities indicate larger sensitivities and therefore the importance of the driver. Small differences in elasticities with respect to flow and demand indicate a balance in the drivers. Table 3 presents the relative change and elasticities metrics for the Missouri, Upper Mississippi, Ohio and the entire Midwest. Table 4 presents the covariances quantifying the reasons of change in supply deficit for the Missouri, Upper Mississippi and Ohio.

\subsubsection{Demand and natural flows}

Figure 8 shows the GCAM mean monthly total water demand for the historical period, 2030s, 2050s and 2080s for the Missouri, Upper Mississippi, Ohio and the entire Upper Midwest for both B1 and A2 scenarios. Figure 9 shows the change in GCAM future total water demands with respect to the historical period. The total water demand keeps increasing over the entire future period over the Missouri (see also Table 3), up to $60 \%$ over the irrigation season. GCAM projects the total demand to significantly increase by the 2030s and keep increasing for A2 but with a slower increase thereafter to the 2050s and then for B1 only to stagnate by the 2080s over the Ohio and Upper Mississippi (Table 3). The Upper Mississippi and Ohio have the largest relative increase in demand during summer time, up to $75 \%$ for $\mathrm{B} 1$ and $90 \%$ for $\mathrm{A} 2$ (Fig. 9). 
Table 2. Percent change in annual discharge of the simulated regulated flow with respect to the simulated natural discharge.

\begin{tabular}{lrrrr|rrr}
\hline Station Name & \multicolumn{3}{c|}{ B1 } & \multicolumn{3}{c}{ A2 } \\
\cline { 2 - 7 } & historical & $2030 \mathrm{~s}$ & $2050 \mathrm{~s}$ & $2080 \mathrm{~s}$ & $2030 \mathrm{~s}$ & $2050 \mathrm{~s}$ & $2080 \mathrm{~s}$ \\
\hline Missouri at Hermann & $-28 \%$ & $-32 \%$ & $-35 \%$ & $-34 \%$ & $-29 \%$ & $-34 \%$ & $-36 \%$ \\
Upper Mississippi at Grafton & $-2 \%$ & $-2 \%$ & $-2 \%$ & $-3 \%$ & $-2 \%$ & $-2 \%$ & $-1 \%$ \\
Ohio at Metropolis & $-8 \%$ & $-10 \%$ & $-11 \%$ & $-10 \%$ & $-9 \%$ & $-10 \%$ & $-9 \%$ \\
US Midwest & $-10 \%$ & $-11 \%$ & $-13 \%$ & $-12 \%$ & $-10 \%$ & $-11 \%$ & $-10 \%$ \\
\hline
\end{tabular}
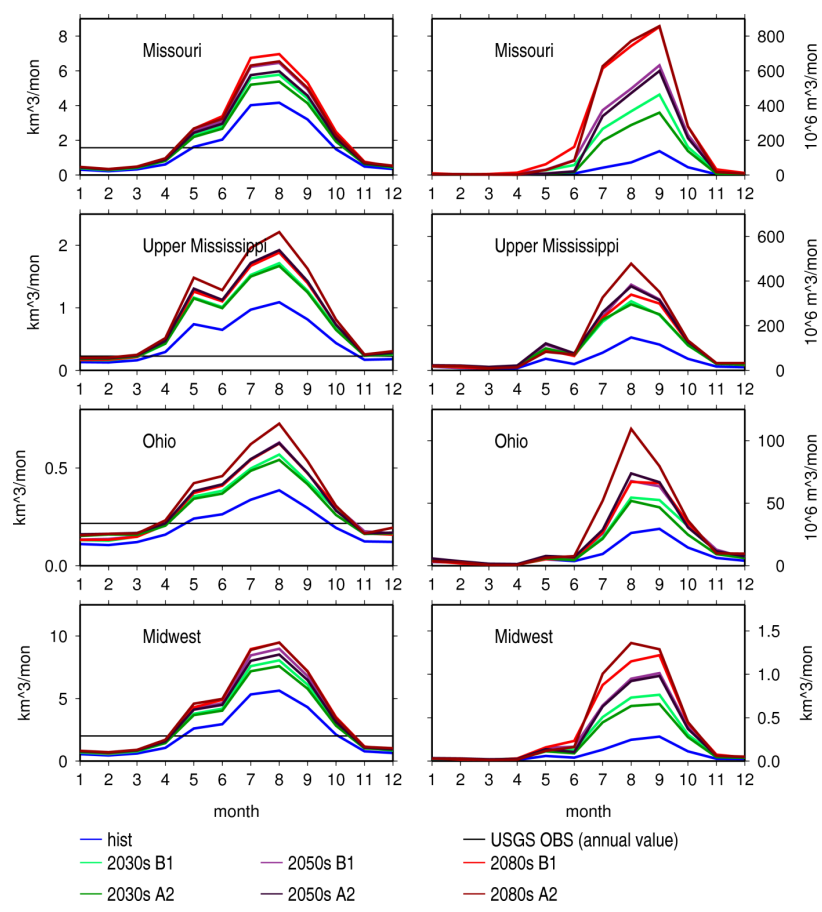

Fig. 8. Monthly average of total water demand (left), and supply deficit (right) over the three regions and over the entire domain for different time periods.

GCAM projects the consumptive irrigation demand to keep increasing over the US Midwest while the nonirrigation consumptive demand increased at a very slow and approximately constant rate (Fig. 5a and b). With the fraction of irrigation demand over the total demand decreasing over the Ohio and Upper Mississippi in the future (Table 5), the demand plateau over the two regions is associated with domestic and thermoelectric demands based on a population projected to stagnate by 2050 in the B1 and A2 scenarios. The steady increase in irrigation water withdrawal (Fig. 5) in the US Midwest is primarily attributed to the projected expansion of biomass, especially in the second half of the 21 st century. One the other hand, the projected reduction in total non-irrigation water withdrawal is mainly attributed to the technological change of water cooling technologies for electricity generation (Fig. 5); i.e., the phasing out of once-through cooling technology and the greater prevalence of more water efficient cooling technologies such as recirculating towers and cooling ponds. Although the total water withdrawal results also encompass the effects of population growth, income effect, fuel mix, energy demand, and climate mitigation, the effects of cooling technology dominated the direction of the change. Since recirculating technologies generally withdraw much less but consume more water than once-through cooling, the total consumptive use for nonirrigation, unlike withdrawals, shows a slight increase.

We force SCLM-MOSART with the downscaled GFDL B1 and GFDL A2 future meteorological forcings. Figure 10 shows the predicted naturalized flow due to climate change over the three regions. Figure 10 and Table 3 show the monthly and annual relative change of natural flow with respect to the historical simulations. The region is predicted to have a warmer climate and overall more precipitation, leading to an overall increased annual natural flow, and higher snowmelt while summer flows decrease (Fig. 10). The increased annual flow, higher snowmelt and lower summer flow tend to be similar between the 2030s and 2050s but further accentuate by the 2080s. The effects of climate change on natural flow over the US Midwest are consistent with the findings of others (Mishra et al., 2010; CCSP, 2008).

We further force SCLM-MOSART-WM with the downscaled GFDL B1 and A2 future meteorological forcing with GCAM demand corresponding to the downscaled GFDL B1 and GFDL A2 scenario emission climates.

\subsubsection{Flow regulation}

Figure 10 shows the projected mean monthly regulated flow for future periods and the relative change in regulated flow with respect to the historical regulated flows. The change in operations is not taken into account as operating rules are calibrated using the historical demands and flows (see discussion). The relative changes in monthly regulated flow (solid line) due to changes in climate (GFDL-B1, GFDL-A2) and demands (GCAM-B1 and GCAM-A2) are projected to be very close to the relative change in natural flow (dashed) due to climate change only over the Ohio and Upper Mississippi basins. The elasticities of the regulated flow with respect to natural flow and demand in Table 3 show that changes in regulated flow over the Upper Mississippi are driven by changes 
Table 3. Relative change in annual discharge, water demand, water supply and supply deficit with respect to the historical period. Elasticities of water supply and supply deficit to changes in demand or discharge with respect to the historical period.

\begin{tabular}{|c|c|c|c|c|c|c|c|c|}
\hline Missouri & & historical & $\begin{array}{r}2030 \mathrm{~s} \\
\mathrm{~B} 1\end{array}$ & $\begin{array}{r}2050 \mathrm{~s} \\
\mathrm{~B} 1\end{array}$ & $\begin{array}{r}2080 \mathrm{~s} \\
\mathrm{~B} 1\end{array}$ & $\begin{array}{r}2030 \mathrm{~s} \\
\mathrm{~A} 2\end{array}$ & $\begin{array}{r}2050 \mathrm{~s} \\
\mathrm{~A} 2\end{array}$ & $\begin{array}{r}2080 \mathrm{~s} \\
\mathrm{~A} 2\end{array}$ \\
\hline \multicolumn{9}{|l|}{ Relative change in } \\
\hline & reg flow at Hermann & \multirow{12}{*}{$2 \%$} & $9 \%$ & $2 \%$ & $14 \%$ & $10 \%$ & $-5 \%$ & $-7 \%$ \\
\hline & flow at Hermann & & $14 \%$ & $13 \%$ & $24 \%$ & $11 \%$ & $3 \%$ & $4 \%$ \\
\hline & Water demand & & $38 \%$ & $54 \%$ & $65 \%$ & $30 \%$ & $44 \%$ & $57 \%$ \\
\hline & Water supply & & $33 \%$ & $46 \%$ & $53 \%$ & $27 \%$ & $37 \%$ & $46 \%$ \\
\hline & Supply deficit & & $343 \%$ & $504 \%$ & $785 \%$ & $212 \%$ & $411 \%$ & $711 \%$ \\
\hline Relative supply deficit & & & $5 \%$ & $7 \%$ & $9 \%$ & $4 \%$ & $6 \%$ & $9 \%$ \\
\hline Elasticity reg flow/nat flow & & & 0.63 & 0.17 & 0.58 & 0.95 & -1.48 & -1.67 \\
\hline Elasticity reg flow/demand & & & 0.23 & 0.04 & 0.21 & 0.33 & -0.11 & -0.12 \\
\hline Elasticity deficit/demand & & & 9.00 & 9.42 & 12.01 & 6.96 & 9.36 & 12.39 \\
\hline Elasticity deficit/runoff & & & 25.02 & 37.37 & 32.41 & 19.69 & 125.97 & 177.15 \\
\hline Elasticity supply/demand & & & 0.86 & 0.86 & 0.81 & 0.89 & 0.85 & 0.80 \\
\hline \multirow[t]{2}{*}{ Elasticity supply/runoff } & & & 2.40 & 3.39 & 2.19 & 2.53 & 11.44 & 11.38 \\
\hline & & \multirow[b]{2}{*}{ historical } & $2030 \mathrm{~s}$ & $2050 \mathrm{~s}$ & $2080 s$ & 2030s & $2050 \mathrm{~s}$ & $2080 \mathrm{~s}$ \\
\hline Upper Mississippi & & & B1 & B1 & B1 & $\mathrm{A} 2$ & $\mathrm{~A} 2$ & $\mathrm{~A} 2$ \\
\hline \multicolumn{9}{|l|}{ Relative Change in } \\
\hline & reg flow at Grafton & \multirow{12}{*}{$8 \%$} & $9 \%$ & $4 \%$ & $13 \%$ & $21 \%$ & $13 \%$ & $17 \%$ \\
\hline & flow at Grafton & & $8 \%$ & $4 \%$ & $13 \%$ & $21 \%$ & $13 \%$ & $15 \%$ \\
\hline & Water demand & & $60 \%$ & $75 \%$ & $73 \%$ & $51 \%$ & $71 \%$ & $93 \%$ \\
\hline & Water supply & & $51 \%$ & $63 \%$ & $64 \%$ & $45 \%$ & $62 \%$ & $83 \%$ \\
\hline & Supply deficit & & $165 \%$ & $213 \%$ & $187 \%$ & $114 \%$ & $159 \%$ & $186 \%$ \\
\hline Relative supply deficit & & & $13 \%$ & $14 \%$ & $13 \%$ & $13 \%$ & $14 \%$ & $14 \%$ \\
\hline Elasticity reg flow/nat flow & & & 1.01 & 1.04 & 1.00 & 1.02 & 1.01 & 1.11 \\
\hline Elasticity reg flow/demand & & & 0.14 & 0.05 & 0.17 & 0.41 & 0.18 & 0.18 \\
\hline Elasticity deficit/demand & & & 2.73 & 2.83 & 2.54 & 2.22 & 2.24 & 2.01 \\
\hline Elasticity deficit/runoff & & & 19.39 & 59.44 & 14.79 & 5.56 & 12.39 & 12.39 \\
\hline Elasticity supply/demand & & & 0.85 & 0.84 & 0.87 & 0.87 & 0.87 & 0.89 \\
\hline \multirow[t]{2}{*}{ Elasticity supply/runoff } & & & 6.03 & 17.64 & 5.03 & 2.18 & 4.81 & 5.52 \\
\hline & & & $2030 \mathrm{~s}$ & $2050 \mathrm{~s}$ & $2080 \mathrm{~s}$ & 2030 s & $2050 \mathrm{~s}$ & $2080 \mathrm{~s}$ \\
\hline Ohio & & historical & $\mathrm{B} 1$ & $\mathrm{~B} 1$ & B1 & $\mathrm{A} 2$ & A2 & A2 \\
\hline \multicolumn{9}{|l|}{ Relative Change in } \\
\hline & reg flow at Metropolis & & $13 \%$ & $2 \%$ & $19 \%$ & $12 \%$ & $11 \%$ & $24 \%$ \\
\hline & flow at Metropolis & & $15 \%$ & $6 \%$ & $21 \%$ & $13 \%$ & $13 \%$ & $24 \%$ \\
\hline & Water demand & & $43 \%$ & $53 \%$ & $51 \%$ & $39 \%$ & $53 \%$ & $69 \%$ \\
\hline & Water supply & & $40 \%$ & $49 \%$ & $47 \%$ & $38 \%$ & $50 \%$ & $63 \%$ \\
\hline & Supply deficit & & $132 \%$ & $169 \%$ & $166 \%$ & $68 \%$ & $130 \%$ & $197 \%$ \\
\hline Relative supply deficit & & $4 \%$ & $6 \%$ & $6 \%$ & $6 \%$ & $5 \%$ & $7 \%$ & $8 \%$ \\
\hline Elasticity reg flow/nat flow & & & 0.85 & 0.40 & 0.87 & 0.94 & 0.84 & 0.99 \\
\hline Elasticity reg flow/demand & & & 0.30 & 0.04 & 0.36 & 0.30 & 0.21 & 0.34 \\
\hline Elasticity deficit/demand & & & 3.09 & 3.17 & 3.24 & 1.75 & 2.43 & 2.87 \\
\hline Elasticity deficit/runoff & & & 8.60 & 28.87 & 7.83 & 5.42 & 9.90 & 8.24 \\
\hline Elasticity supply/demand & & & 0.92 & 0.92 & 0.92 & 0.97 & 0.93 & 0.91 \\
\hline \multirow[t]{2}{*}{ Elasticity supply/runoff } & & & 2.57 & 8.39 & 2.22 & 3.00 & 3.81 & 2.63 \\
\hline & & & $2030 \mathrm{~s}$ & $2050 \mathrm{~s}$ & $2080 \mathrm{~s}$ & 2030 s & $2050 \mathrm{~s}$ & $2080 \mathrm{~s}$ \\
\hline US Midwest & & historical & B1 & B1 & B1 & $\mathrm{A} 2$ & $\mathrm{~A} 2$ & $\mathrm{~A} 2$ \\
\hline \multicolumn{9}{|l|}{ Relative Change in } \\
\hline & flow & & $12 \%$ & $6 \%$ & $18 \%$ & $16 \%$ & $11 \%$ & $15 \%$ \\
\hline & Water demand & & $43 \%$ & $58 \%$ & $66 \%$ & $36 \%$ & $51 \%$ & $66 \%$ \\
\hline & Water supply & & $37 \%$ & $49 \%$ & $55 \%$ & $32 \%$ & $43 \%$ & $55 \%$ \\
\hline & Supply deficit & & $228 \%$ & $317 \%$ & $409 \%$ & $142 \%$ & $240 \%$ & $363 \%$ \\
\hline Relative supply deficit & & $3 \%$ & $7 \%$ & $8 \%$ & $10 \%$ & $7 \%$ & $8 \%$ & $10 \%$ \\
\hline Elasticity deficit/demand & & & 5.29 & 5.48 & 6.22 & 3.97 & 4.75 & 5.51 \\
\hline Elasticity deficit/runoff & & & 19.78 & 49.27 & 23.25 & 8.77 & 22.41 & 24.35 \\
\hline Elasticity supply/demand & & & 0.86 & 0.85 & 0.83 & 0.89 & 0.86 & 0.83 \\
\hline Elasticity supply/runoff & & & 3.21 & 7.68 & 3.10 & 1.96 & 4.05 & 3.67 \\
\hline
\end{tabular}


Table 4. Covariances of supply deficit with inflow and water demand. Bold values are significant at the $90 \%$ confidence level.

\begin{tabular}{lrr|rr|rr}
\hline & \multicolumn{2}{c|}{ Missouri } & \multicolumn{2}{|c|}{ Upper Mississippi } & \multicolumn{2}{c}{ Ohio } \\
\cline { 2 - 7 } B1 & demand & inflow & demand & inflow & demand & inflow \\
\hline $2015-2095$ & $\mathbf{1 8 \%}$ & $\mathbf{3 7 \%}$ & $6 \%$ & $\mathbf{3 2 \%}$ & $7 \%$ & $8 \%$ \\
$2030 \mathrm{~s}$ & $3 \%$ & $\mathbf{5 5} \%$ & $13 \%$ & $26 \%$ & $15 \%$ & $1 \%$ \\
$2050 \mathrm{~s}$ & $24 \%$ & $\mathbf{3 7 \%}$ & $0 \%$ & $\mathbf{4 1 \%}$ & $0 \%$ & $6 \%$ \\
$2080 \mathrm{~s}$ & $0 \%$ & $\mathbf{6 1} \%$ & $6 \%$ & $\mathbf{4 1} \%$ & $0 \%$ & $22 \%$ \\
\hline A2 & & & & & & \\
\hline $2015-2095$ & $\mathbf{4 0 \%}$ & $\mathbf{1 7 \%}$ & $15 \%$ & $\mathbf{2 1 \%}$ & $\mathbf{2 5 \%}$ & $1 \%$ \\
$2030 \mathrm{~s}$ & $26 \%$ & $\mathbf{2 8} \%$ & $10 \%$ & $\mathbf{5 0} \%$ & $7 \%$ & $3 \%$ \\
$2050 \mathrm{~s}$ & $3 \%$ & $\mathbf{3 2} \%$ & $6 \%$ & $\mathbf{5 0} \%$ & $4 \%$ & $1 \%$ \\
$2080 \mathrm{~s}$ & $25 \%$ & $7 \%$ & $19 \%$ & $5 \%$ & $2 \%$ & $3 \%$ \\
\hline
\end{tabular}

in natural flow and are of equal magnitude for both B1 and A2, with elasticities close to 1. Elasticities of regulated flow with respect to natural flow for the Ohio are lower for B1 but close to 1 for A2 as well. The changes in demand have effect on the regulated flows but are less than two to three times the impact of change in natural flow, as shown by the ratio of elasticities. Over the Missouri in July, August and September, starting in the 2050s, the change in regulated flow (climate and demand) is twice the magnitude, or same magnitude but of opposite effect, compared to the change in naturalized flow. The summer Missouri regulated flow is impacted by changes in natural flow and demand. On an annual timescale, changes in regulated flow over the Missouri are driven by changes in natural flow but not as much as the two other regions (covariances not shown). Elasticities with respect to natural flow and demand are also much closer to each other. Note, however, that the regulated flow is predicted to decrease in future period for A2. All Missouri elasticities with respect to natural flow in Table 3 increase tremendously as the system reaches its limit for actual supply so the natural flow also becomes the main driver of changes. Note also that the GCAM demand is not constrained by water availability.

\subsubsection{Supply}

Figure 8 shows the projected mean monthly water supply deficit over the Missouri, Upper Mississippi, Ohio, and Upper Midwest. Figure 9 shows the change in relative water supply deficit, which characterizes the need for and the reliance on an additional source of water supply in the future. The supply deficit is expected to keep increasing over the Missouri River basin, stagnate over the Ohio by the 2050s, and slow in its increase in the Upper Mississippi (Table 3). The largest demand being over the Missouri, the supply deficit over the entire Upper Midwest follows its increasing trend. The end of the summer is the most vulnerable period. In terms of the relative supply deficit and dependence on other source of supply, the Missouri is projected to experience its dependence jump from below $5 \%$ to up to $15 \%$ by 2080s for the month of September for both scenarios. The
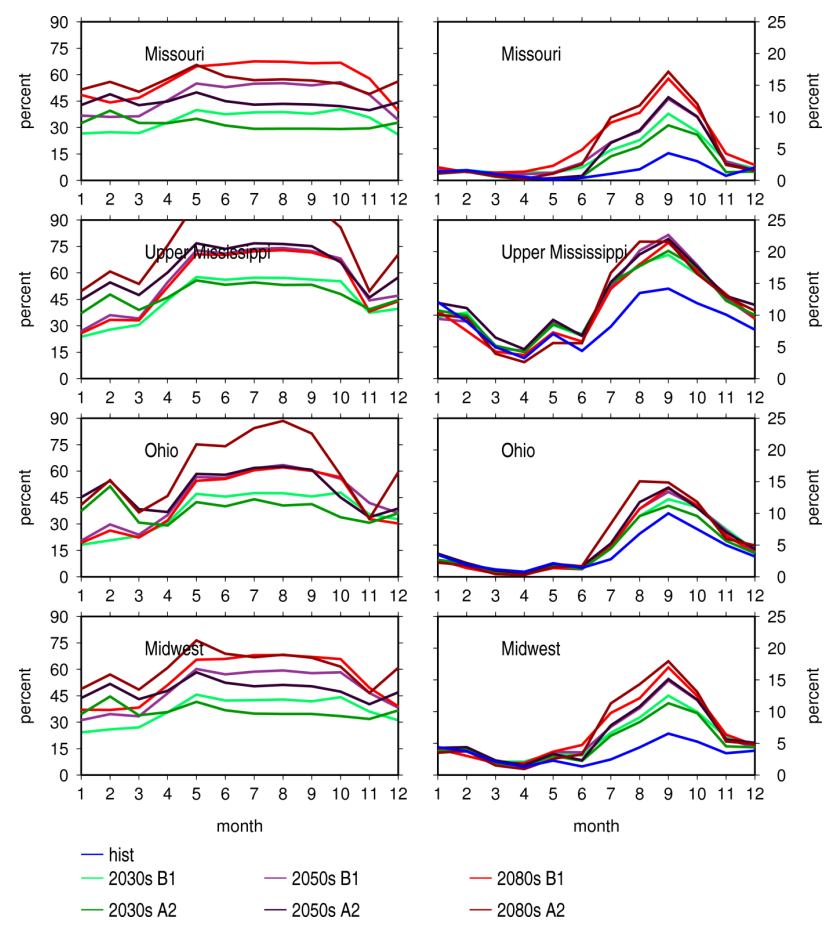

$$
\begin{array}{ll}
-2030 \mathrm{~s} B 1 & -2050 \mathrm{~s} B 1 \\
-2030 \mathrm{~s} A 2 & -2050 \mathrm{~s} \mathrm{~A} 2
\end{array}
$$$$
-2080 \text { s B1 }
$$

Fig. 9. relative change in total GCAM demand with respect to the historical demand for the three regions (left), and regional mean monthly fractional water supply deficit - or reliance on another water supply - for historical and future periods.

Missouri has the largest increase in annual relative supply deficit from $2 \%$ for the historical period to $9 \%$ by the 2080 s in both scenarios, but the Upper Mississippi River basin has the largest dependencies, changing from $9 \%$ historically to $14 \%$ by the 2080 s, for both scenarios as well (Table 3 ).

Table 4 shows the covariances of supply deficit with future natural flow and water demand for the Missouri, Upper Mississippi and Ohio and both scenarios. Over the 20152095 period, the supply deficit over the Missouri is explained by the future flow and the water demand because the supply deficit goes through a steady increase following the water demand pattern (Fig. 5). Over shorter time periods, the variance in supply deficit is explained by the flow. Noteworthy is that our water demand presently has no interannual variability but there is a steady increase in the long term. Interannual variability should vary with global markets and water availability that will be the object of the two-way coupling in progress. Over the Upper Mississippi, the supply deficit is driven by the flow given the low storage capacity. Over the Ohio River basin there is no significant covariance except with water demand over a long period with the A2 scenario. Like the Upper Mississippi, the storage capacity is limited over the Ohio and the flow would be expected to drive the supply deficit. However, the water demand over the Ohio is mostly for nonirrigation use and is more localized. The low covariances are due to the specificity of the Ohio region, with the available 
Table 5. Fraction of total demand attributed to the irrigation sector.

\begin{tabular}{|c|c|c|c|c|c|c|c|c|}
\hline \multirow{2}{*}{ Period } & \multicolumn{4}{|c|}{ B1 } & \multicolumn{4}{|c|}{$\mathrm{A} 2$} \\
\hline & Midwest & Missouri & Ohio & $\begin{array}{r}\text { Upper } \\
\text { Mississippi }\end{array}$ & Midwest & Missouri & Ohio & $\begin{array}{r}\text { Upper } \\
\text { Mississippi }\end{array}$ \\
\hline Hist & 0.8 & 0.9 & 0.35 & 0.75 & 0.8 & 0.9 & 0.35 & 0.75 \\
\hline $2030 \mathrm{~s}$ & 0.82 & 0.9 & 0.44 & 0.8 & 0.83 & 0.9 & 0.42 & 0.79 \\
\hline $2050 \mathrm{~s}$ & 0.84 & 0.92 & 0.47 & 0.81 & 0.85 & 0.91 & 0.47 & 0.81 \\
\hline $2080 \mathrm{~s}$ & 0.85 & 0.93 & 0.42 & 0.71 & 0.76 & 0.81 & 0.46 & 0.74 \\
\hline
\end{tabular}

water not reachable by the demanding areas, as shown next. Similarly, the lack of interannual variability in the demand explains the low covariance of supply deficit with demand over shorter periods.

Figure 11 displays the spatial distribution of the GCAM annual consumptive water demand, the simulated SCLMMOSART-WM water supply, and the corresponding relative supply deficit for the historical and B1 future periods. The GCAM demands are projected to increase in particular over the Platte River and urban area over the Ohio and Upper Mississippi river basins. The supply increases where the demand increases. However, the supply deficit does not obviously overlay the regions with the highest demand, but rather seems to reflect a combination of demand and water availability, i.e., upstream of the Osage River and the urban areas adjacent to the Great Lakes.

\section{Discussion}

In view of the results and methodology, we highlight three areas of discussion: (i) the sensitivity of the integrated modeling results with respect to hydrologic and other modeling errors; (ii) drivers of change in projected stream discharge and ability to meet the water demand; and (iii) reconciliation of SCLM and GCAM water balances through the input of withdrawals in addition to consumptive demand, groundwater supply, and full coupling between WM and SCLM and water allocation when demands exceed water availability.

\subsection{Modeling errors}

The SCLM-MOSART simulations driven by the downscaled GFDL historical climate produced an overall underestimation of the observed naturalized flow at Hermann. Table 6 shows the regional water balance of the GFDL-SCLMMOSART simulations compared to the SCLM-MOSART simulations driven by the NLDAS2 forcing data. The downscaled GFDL climate is drier and has higher net radiation compared to NLDAS2, with the differences larger in 19841999 than 1976-1999. This results in lower runoff in GFDLSCLM-MOSART than NLDAS-SCLM-MOSART. The bias in the downscaled GFDL climate is not surprising, as very little constraints are used in the global climate simulations.
Table 6. Water balance comparison of GFDL against NLDAS ( $P=$ precipitation; $R=$ total runoff; ET $=$ evapotranspiration) for the Upper Midwest region.

\begin{tabular}{lr|rrr}
\hline & GFDL & \multicolumn{3}{c}{ NLDAS } \\
\cline { 2 - 5 } & $1984-1999$ & $1976-1999$ & $1984-1999$ & $1979-2008$ \\
\hline$P$ & 688 & 693 & 712 & 712 \\
$R$ & 157 & 162 & 198 & 195 \\
ET & 525 & 531 & 516 & 516 \\
$R+$ ET & 683 & 693 & 714 & 712 \\
$P-(R+\mathrm{ET})$ & 5.1 & 0.4 & -2.5 & 0.7 \\
\hline
\end{tabular}

Even statistical downscaling methods such as the constructed analog cannot fully remove the biases in the climate simulations. Using an ensemble of climate models may reduce the overall biases, but this is beyond of the scope of this study. The runoff coefficients, however, are similar to those extracted from the Maurer et al. (2002) simulations, which are often used as reference. Despite the simulation biases, the numerical experiments reported here showed proof of concept in one-way coupling of a terrestrial system model that includes a land surface model, river routing model and water resources management with a water demand model, which is part of a global integrated assessment model. Our results showed reasonable agreement in simulating the effect of human activities on the land surface system.

The present results focus on projection of water resources based on historical operating rules, that is, no adaptation of reservoir operations to climate change. Previous studies have applied water resources management models under climate change regionally (Hamlet et al., 2010; Christensen et al., 2004; Van Rheenen et al., 2004; Vano et al., 2010a, b) using optimized water resources operations with the full knowledge of future flow. Konar et al. (2013) applied for a first time a future scenario on crop productivity using the Hanasaki et al. (2008) global reservoir model with generic operating rules based on historical conditions as well. Quantifying the sensitivity of updating the operating rules to future flow and demand is a subject for more research. We anticipate that updating the operating rules for flow over a dependent period, i.e., equivalent to optimization, could affect the supply deficit results in this research. Sensitivity should be 


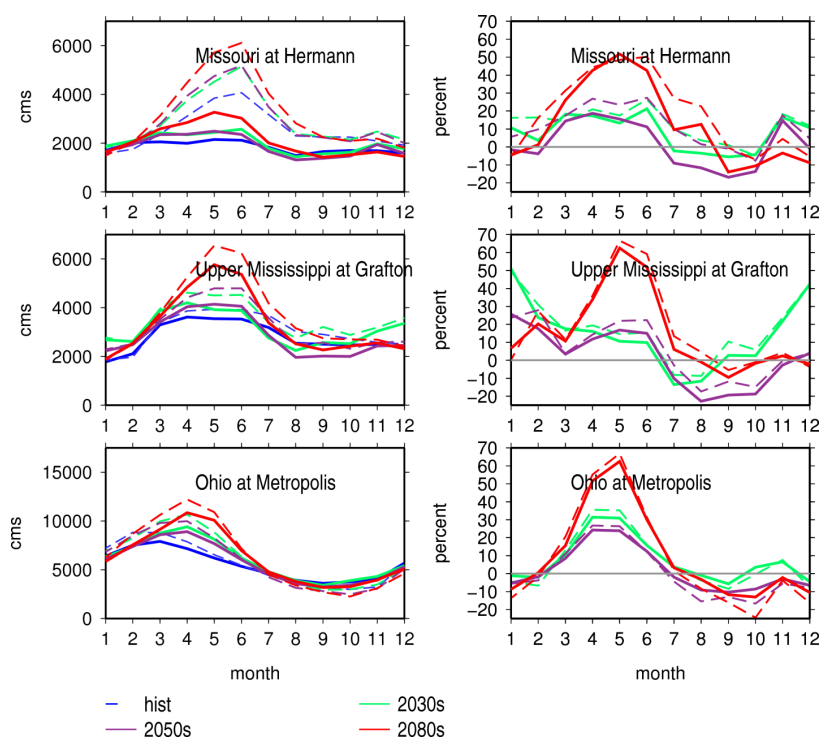

Fig. 10. Left column: simulated mean monthly natural (dashed) and regulated (solid) flow at Hermann, Grafton and Metropolis for different time periods: historical (1998-1999), 2030s B1 (2015-2045), 2050s B1 (2035-2065) and 2080s B1 (2065-2095). Right column: relative change in mean monthly flow of natural (dashed) and regulated (solid) flow for future B1 periods with respect to their historical counterparts. Results with A2 emission scenario were similar.

a function of changes in monthly natural flow and storage capacity over the region and reservoir uses.

\subsection{Drivers of change in future human effects on land surface system}

The human activities are represented by a water management model and a global integrated assessment model that simulates water demand. Rainfed crop demand is handled directly by the land surface modeling component. We investigate the drivers of the change in regulated flow and supply deficit using covariances (Table 4) and elasticities (Table 3) with respect to climate-induced change in natural flow and changes in water demand driven by socioeconomic factors, energy and food demands, global markets and prices. Figure 12 also presents scatterplots of annual change in regulated discharge and annual relative change in supply deficit.

Over the Ohio River basin, the demand is localized over specific urban areas (Fig. 11) and exceeds the locally available water. Cities might be located too far from the main stem from which they could request water from reservoir releases. Mostly, the reservoir storage along the main stem does not allow much regulation at the monthly timescale (Figs. 1, 6 and 7). Because of the limited storage capacity of the reservoirs over the Ohio River, a relatively low demand, and cities with high demand but too far from the main stem to access the water supply according to our database rules, climate change effects on the natural flow drive the change in regulated flow
(Fig. 9) with changes being of about equal magnitude (elasticities close to 1). Changes in supply deficit are driven by changes in demand regionally but are driven by a combination of changes in runoff and demand locally around the high demand urban areas. For B1, the elasticity of the supply deficit with respect to changes in demand stagnates around 3 . Relative to changes in flow, the elasticity is more uncertain, with a higher range of fluctuation between 5.4 and 28.9. However, supply deficit over the Ohio is the least sensitive to changes in flow and demand than the other regions (Fig. 12 and Table 4).

Over the Upper Mississippi River basin, the increase in demand with increasing supply deficit is localized over the urban and agricultural areas adjacent to the Great Lakes. There are cities like St. Louis along the main stem that actually have very small, or almost no supply deficit (Fig. 11). Changes in regulated flow are driven by changes in natural flow, with elasticities close to 1 (Table 3 ) due to the limited storage capacity, relatively low demand with respect to the annual flow and cities and fields too far from the main stem, like over the Ohio River basin. Elasticities with respect to changes in demand are small (between 0.05 and 0.41). The increases in supply deficit are driven primarily by the change in runoff, as seen in Fig. 12 and Table 4. Elasticities of supply deficit with respect to flow, however, are more uncertain as they range between 5 and 60 , while elasticities with respect to demand stagnate between 2 and 3 .

Over the Missouri River basin, the increase in demand is spread out with a large demand along the Platte River valley (Fig. 11). However, the supply deficit is mostly localized over the headwaters of the Platte River. As seen in Voisin et al. (2013), an excessive surface water demand can drive upstream reservoir dry leaving headwater areas with a supply deficit. The area is relying significantly on groundwater pumping with $26 \%, 11 \%, 7 \%$ of withdrawals over the Missouri and Upper Mississippi and Ohio respectively coming from groundwater, although how much groundwater comes from confined aquifers has not been specified (Kenny et al., 2009). Voisin et al. (2013) recommend to adjust the withdrawals and consumptive use demand on the surface water system for groundwater. The sensitivity to the fraction of irrigation groundwater use is the focus of further research. With regulated runoff being affected by a combination of change in natural flow and in demand (Fig. 9), Fig. 12 links the change in supply deficit to the change in regulated runoff, i.e., changes in natural flow and demand. The supply deficit over the Missouri is controlled mostly by the natural flow over shorter periods and demand over longer periods (Table 4). The Missouri is the most sensitive to changes in runoff and demand, showing the largest elasticities with respect to both flow and demand. The change in runoff is still the predominant driver of the change in supply deficit, especially under $\mathrm{A} 2$ when the system seems to reach its supplying limit. However, sensitivity of supply deficit to changes in demand should be taken into consideration for climate change impact 


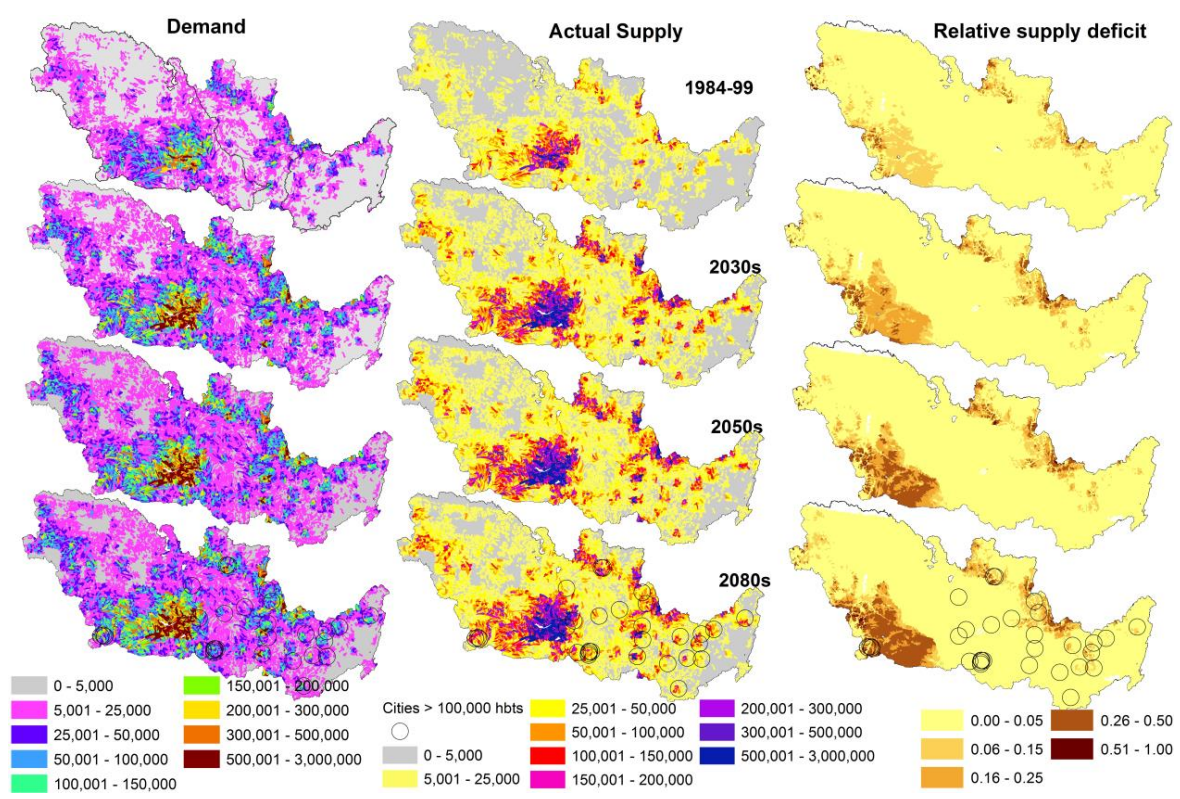

Fig. 11. Annual total water demand (left) and actual water supply (center) in cubic meters, and fractional water supply deficit for historical and future B1 periods.

assessment given that about $21 \%$ of the annual flow is consumed.

For the US Midwest, it is important to note that supply deficit is around six times as sensitive to changes in runoff and demand than the actual supply; it increases to 10 times over the Missouri and decreases to 3 times over the Ohio and Upper Mississippi. This emphasizes the predicted competition between water uses in the future and the importance to look at the water demand driven by socioeconomics factors and global markets. It is also noteworthy to look at the range of elasticities of the supply deficit with respect to flow and demand over future periods and between a pessimistic A2 scenario and an optimistic B1 scenario, in particular from 2050s to 2080s when the A2 and B1 climate scenarios tend to significantly diverge. The range of elasticities show the complex interactions between changes in climate-induced natural flow, socioeconomics changes in water demand, the storage capacity of the region and the reservoir model regulation and extraction.

\subsection{Water balance}

GCAM uses an independent model different from SCLM to simulate water balance so GCAM's estimates of water demands may be inconsistent with the water availability in SCLM. This can be resolved once a two-way (full) coupling between GCAM and SCLM-MOSART-WM is established, where the latter provides the amount of water availability and thus constraining water demands in GCAM (Tamea et al., 2013; Konar et al., 2013). However, we also need to quantify how much groundwater comes from unconfined aquifer and how much comes from return flow for adjusting the demand on the surface water system. Similarly, in order to use withdrawals more research focused on the full coupling of the water resources management model with the land surface hydrology model is needed.

\section{Conclusions}

In this paper, a temporal downscaling methodology is developed in order to facilitate the coupling of a global integrated assessment model (GCAM) with a land surface scheme-routing-water resources management model (SCLM-MOSART-WM). This one-way coupling is a step towards a fully coupled modeling framework to model hydrologic impacts and water management options in an integrated human-earth system model. The goal of this first step is to implement the data exchange between the global integrated assessment model and the land surface, river routing, and water management model, and to address scale mismatch between the models. We also demonstrate the need to consider water demand driven by socioeconomic factors, energy and food demands, global markets for a more accurate representation of the anthropogenic influence, especially in areas with significant urbanization and agriculture affected by global markets. The evaluation of the integrated system is performed over three regions of the Upper Midwest: the Missouri, Upper Mississippi and Ohio river basins, focusing on the changes from natural to regulated flows, changes in demand and fractional supply deficit. 

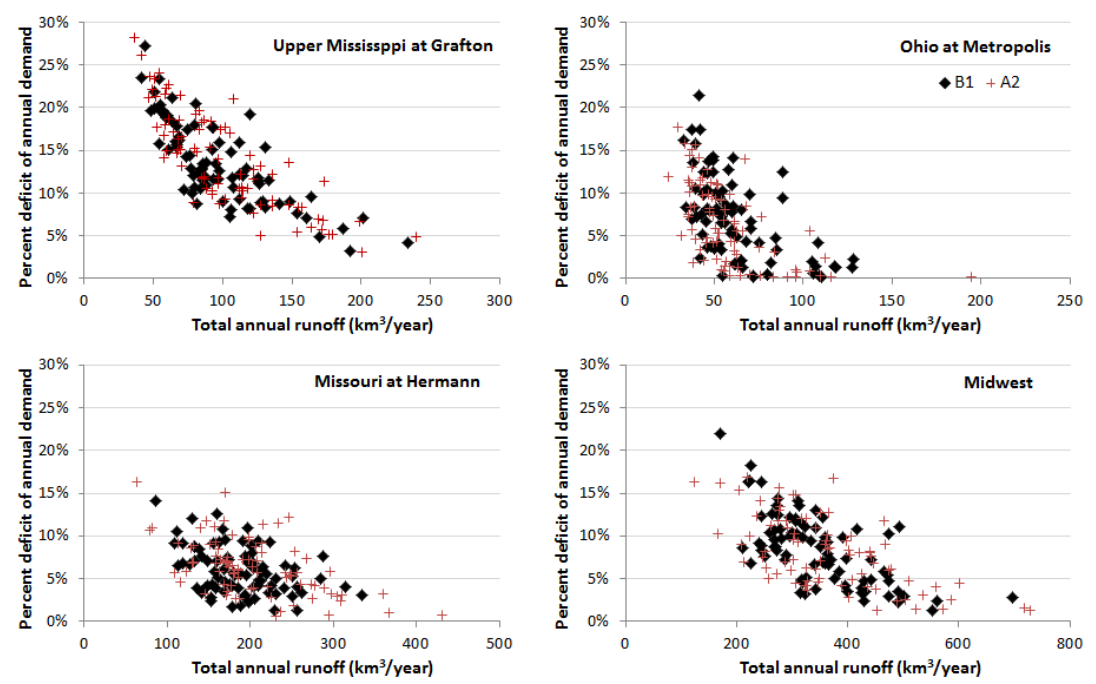

Fig. 12. Relationship between total annual regulated runoff and percent deficit of annual water demand for the historical and future B1 (black diamonds) and A2 (red cross) simulations, over the three regions and the Upper Midwest.

a. Over the historical period, the integrated system is reasonably well reproducing the anthropogenic influence on the flow and the water supply over the three regions.

b. Implications for future water resources affected by the human influence are driven by changes in the water demands simulated by GCAM and the change in flow (climate change). With the Upper Midwest projected (GFDL-B1 and GFDL-A2) to have an increased in annual flow and in particular snowmelt flows.

c. There is uncertainty in the direction of the mean annual regulated flow. The annual regulated flow is projected to slightly increase with B1 but decrease with A2. Seasonally, the regulated flow is projected to increase over the snowmelt period (A2 and B1) and remain similar (B1) or lower (A2) to historical regulated flow during the summer.

d. The actual supply is also projected to increase but not enough to compensate for the increase in demand, i.e., the relative supply deficit is projected to increase over the region. The largest relative supply deficit is simulated over the Upper Mississippi.

e. Drivers of the changes in regulated flow are the changes in the natural flow due to climate change for the Ohio and Upper Mississippi, and a combination of changes in socioeconomic factors that drive changes in water demand and climate change that drives changes in natural flow over the Missouri Over the Missouri, both changes in flow and demand need to be taken into consideration for projecting future water resources.

f. Supply deficit is 6 times more sensitive to changes in natural flow and demand than water supply is. Drivers of the change in supply deficit are the changes in natural flow over the US Midwest in general, and over the Upper Mississippi. The change in supply deficit over the Ohio is driven by the change in demand that is very localized around urban areas. The change in supply deficit over the Missouri, however, is driven by a combination of change in demand and in natural flow.

Over the US Midwest where the natural flow is projected to increase and the crop is mostly rain fed, changes in regulated flow and supply, and supply deficit are driven by the change in runoff due to climate change, more than the change in socioeconomic water demands. Regionally, however, the modeling of water demands allows us to isolate sectors and areas that will be more sensitive to change in demand and will rely on groundwater and virtual water trade. Over areas relying more heavily on irrigation, we anticipate a stronger signal between the change in demand and change in supply deficit and flow regulation. The sensitivity analysis of supply deficit with respect to changes in flow and demand shows the complex interactions between changes in climate-induced natural flow, socioeconomics changes in water demand, the storage capacity of the region and the reservoir model regulation and extraction. The study presents a successful one-way coupling of a global integrated assessment model with a regional scale hydrologic and water management model. Future work will focus on the effect of hydrologic errors and on updating the reservoir module operating rules over more regions.

Acknowledgements. The authors would like to thank S. Siebert at the University of Bonn, Germany for providing the global gridded monthly irrigation water requirements data for crops, and Duane Ward at the Pacific Northwest National Laboratory (PNNL) for his assistance with the WM dependence database set up over the US 
Midwest. We thank two anonymous reviewers and editor W. Buytaert for their constructive criticism that significantly improved the manuscript. This study was supported by PNNL's Platform for Regional Integrated Modeling and Analysis (PRIMA). The authors wish to express appreciation to the Integrated Assessment Research Program in the Office of Science of the US Department of Energy (DOE) for long-term support that enabled the development of the Global Change Assessment Model, which was used in the conduct of this research. PNNL is operated by Battelle for the US DOE under contract DE-AC05-76RL01830. The views and opinions expressed in this paper are those of the authors alone.

Edited by: W. Buytaert

\section{References}

Allen, R. P. and Soden, B. J.: Atmospheric warming and the amplification of precipitation extremes, Science, 321, 1481-1484, doi:10.1126/science.1160787, 2008.

Backlund, P., Janetos, A., Schimel, D., Hatfield, J., Boote, K., Fay, P., Hahn, L., Izaurralde, C., Kimball, B. A., Mader, T., Morgan, J., Ort, D., Polley, W., Thomson, A., Wolfe, D., Ryan, M., 25 Archer, S., Birdsey, R., Dahm, C., Heath, L., Hicke, J., Hollinger, D., Huxman, T., Okin, G., Oren, R., Randerson, J., Schlesinger, W., Lettenmaier, D., Major, D., Poff, L., Running, S., Hansen, L., Inouye, D., Kelly, B. P., Meyerson, L, Peterson, B., and Shaw, R.: The Effects of Climate Change on Agriculture, Land Resources, Water Resources, and Biodiversity in the United States, Chapter, A Report by the US Climate Change Science Program and the Subcommittee on Global Change Research, US Environmental Protection Agency, Washington D.C., USA, 2008.

Biemans, H., Haddeland, I., Kabat, P., Ludwig, F., Hutjes, R. W. A., Heinke, J., von Bloh, W., and Gerten, D.: 5 Impact of reservoirs on river discharge and irrigation water supply during the 20th century, Water Resour. Res., 47, W03509, doi:10.1029/2009WR008929, 2011.

Brenkert, A., Smith, S., Kim., S., and Pitcher, H.: Model Documentation for the MiniCAM. PNNL-14337, Pacific Northwest National Laboratory, Richland, Washington, 2003.

Calvin, K., Wise, M., Clarke, L., Edmonds, J., Kyle, P., Luckow, P., and Thomson, A.: Implications of simultaneously mitigating and adapting to climate change: initial experiments using GCAM, Climatic Change, 117, 545-560, doi:10.1007/s10584-012-0650y, 2013.

CCSP: The Effects of Climate Change on Agriculture, Land Resources, Water Resources, and Biodiversity in the United States. A Report by the US Climate Change Science Program and the Subcommittee on Global Change Research, edited by: Backlund, P., Janetos, A., Schimel, D., Hatfield, J., Boote, K., Fay, P., Hahn, L., Izaurralde, C., Kimball, B. A., Mader, T., Morgan, J., Ort, D., Polley, W., Thomson, A., Wolfe, D., Ryan, M., Archer, S., Birdsey, R., Dahm, C., Heath, L., Hicke, J., Hollinger, D., Huxman, T., Okin, G., Oren, R., Randerson, J., Schlesinger, W., Lettenmaier, D., Major, D., Poff, L., Running, S., Hansen, L., Inouye, D., Kelly, B. P., Meyerson, L., Peterson, B., and Shaw, R., US Environmental Protection Agency, Washington, DC, USA, Chapter 4.3, 2008.

Chaturvedi, V., Hejazi, M. I., Edmonds, J., Clarke, L., Kyle, P., Davies, E., and Wise, M.: Climate mitigation policy implica- tions for global irrigation water demand, Mitig. Adapt. Strategies Glob., Springer, doi:10.1007/s11027-013-9497-4, in press, 2013.

Christensen, N. S., Wood, A. W., Voisin, N., Lettenmaier, D. P., and Palmer, R. N.: Effects of Climate Change on the Hydrology and Water Resources of the Colorado River Basin, Climatic Change, 62, 337-363, 2004.

Clarke, L., Edmonds, J., Jacoby, H., Pitcher, H., Reilly, J., and Richels, R.: CCSP Synthesis and Assessment Product 2.1, Part A: Scenarios of Greenhouse Gas Emissions and Atmospheric Concentrations. US Government Printing Office, Washington D.C., 2007a.

Clarke, L., Lurz, J., Wise, M., Edmonds, J., Kim, S., Smith, S., and Pitcher, H.: Model Documentation for the MiniCAM Climate Change Science Program Stabilization Scenarios: CCSP Product 2.1a, PNNL Technical Report, PNNL-16735, $2007 \mathrm{~b}$.

Cosgrove, B. A., Lohmann, D., Mitchell, K. E., Houser, P. R., Wood, E. F., Schaake, J., Robock, A., Marshall, C., Sheffield, J., Luo, L., Duan, Q., Pinker, R. T., Tarpley, J. D., Higgins, R. W., and Meng, J.: Real-time and retrospective forcing in the North American Land Data Assimilation System (NLDAS) project, J. Geophys. Res., 108, 8842, doi:10.1029/2002JD003118, 2003.

Cuo, L., Beyene, T. K., Voisin, N., Su, F., Lettenmaier, D. P., Alberti, M., and Richey, J. E.: Effects of mid-twenty-first century climate and land cover change on the hydrology of the Puget Sound basin, Washington, Hydrol. Process., 25, 1729 1753, doi:10.1002/hyp.7932, 2011.

Davies, E., Kyle, P., and Edmonds, J.: An integrated assessment of global and regional water demands for electricity generation to 2095, Adv. Water Resour., 52, 296-313, 2013.

Delworth, T. L., Broccoli, A. J., Rosati, A., Stouffer, R. J., Balaji, V., Beesley, J. A., Cooke, W. F., Dixon, K. W., Dunne, J. P., Dunne, K. A., Durachta, J. W., Findell, K. L., Ginoux, P., Gnanadesikan, A., Gordon, C. T., Griffies, S. M., Gudgel, R., Harrison, M. J., Held, I. M., Hemler, R. S., Horowitz, L. W., Klein, S. A., Knutson, T. R., Kushner, P. J., Langenhorst, A. R., Lee, H.-C., Lin, S.J., Lu, J., Malyshev, S., Milly, P. C. D., Ramaswamy, V., Russell, J. L., Schwarzkopf, M. D., Shevliakova, E., Sirutis, J. J., Spelman, M. J., Stern, W. F., Winton, M., Wittenberg, A. T., Wyman, B., Zeng, F., and Zhang, R.: GFDL's CM2 Global Coupled Climate Models. Part I: Formulation and Simulation Characteristics, J. Climate, 19, 19643-19674, doi:10.1175/JCLI3629.1, 2006.

Döll, P., Fiedler, K., and Zhang, J.: Global-scale analysis of river flow alterations due to water withdrawals and reservoirs, Hydrol. Earth Syst. Sci., 13, 2413-2432, doi:10.5194/hess-13-24132009, 2009.

Frans, C., Istanbulluoglu, E., Mishra, V., Munoz-Arriola, F., and Lettenmaier, D. P.: Are climatic or land cover changes the dominant cause of runoff trends in the Upper Mississippi River Basin?, Geophys. Res. Lett., 40, 1104-1110, doi:10.1002/grl.50262, 2013.

Haddeland, I., Lettenmaier, D. P., and Skaugen, T.: Effects of irrigation on the water and energy 5 balances of the Colorado and Mekong River basins, J. Hydrol., 324, 210-223, 2006.

Hamlet, A. F., Lee, S. Y., Mickelson, K. E. B., and Elsner, M. M.: Effects of projected climate change on energy supply and demand in the Pacific Northwest and Washington State, Climatic Change, 102, 103-128, doi:10.1007/s10584-010-9857-y, 2010. 
Hanasaki, N., Kanae, S., and Oki, T.: A reservoir operation scheme for global river routing models, J. Hydrol., 327, 22-41, doi:10.1016/j.jhydrol.2005.11.011, 2006.

Hanasaki, N., Kanae, S., Oki, T., Masuda, K., Motoya, K., Shirakawa, N., Shen, Y., and Tanaka, K.: An integrated model for the assessment of global water resources - Part 1: Model description and input meteorological forcing, Hydrol. Earth Syst. Sci., 12, 1007-1025, doi:10.5194/hess-12-1007-2008, 2008.

Hanasaki, N., Fujimori, S., Yamamoto, T., Yoshikawa, S., Masaki, Y., Hijioka, Y., Kainuma, M., Kanamori, Y., Masui, T., Takahashi, K., and Kanae, S.: A global water scarcity assessment under Shared Socio-economic Pathways - Part 1: Water use, Hydrol. Earth Syst. Sci., 17, 2375-2391, doi:10.5194/hess-17-23752013, 2013.

Hanasaki, N., Fujimori, S., Yamamoto, T., Yoshikawa, S., Masaki, Y., Hijioka, Y., Kainuma, M., Kanamori, Y., Masui, T., Takahashi, K., and Kanae, S.: A global water scarcity assessment under Shared Socio-economic Pathways - Part 2: Water availability and scarcity, Hydrol. Earth Syst. Sci., 17, 2393-2413, doi:10.5194/hess-17-2393-2013, 2013.

Hejazi, M. I., Edmonds, J., Clarke, L., Kyle, P., Davies, E., Chaturvedi, V., Wise, M., Patel, P., Eom, J., Calvin, K., Moss, R., and Kim, S.: Long-term global water use projections using six socioeconomic scenarios in an integrated assessment modeling framework, Technol. Forecast. Soc., in press, doi:10/1016/j.techfore.2013.05.006, 2013a.

Hejazi, M. I., Edmonds, J., Clarke, L., Kyle, P., Davies, E., Chaturvedi, V., Wise, M., Patel, P., Eom, J., and Calvin, K.: Integrated assessment of global water scarcity over the 21 st century - Part 1: Global water supply and demand under extreme radiative forcing, Hydrol. Earth Syst. Sci. Discuss., 10, 3327-3381, doi:10.5194/hessd-10-3327-2013, 2013b.

Hejazi, M. I., Edmonds, J., Clarke, L., Kyle, P., Davies, E., Chaturvedi, V., Eom, J., Wise, M., Patel, P., and Calvin, K.: Integrated assessment of global water scarcity over the 21 st century - Part 2: Climate change mitigation policies, Hydrol. Earth Syst. Sci. Discuss., 10, 3383-3425, doi:10.5194/hessd-10-3383-2013, 2013c.

Hejazi, M. I., Edmonds, J., Chaturvedi, V., Davies, E., and Eom, J.: Scenarios of Global Municipal Water Use Demand Projections over the 21st Century, Hydrolog. Sci. J., 58, 519-538, doi:10.1080/02626667.2013.772301, 2013d.

Held, I. M. and Soden, B. J.: Robust responses of the hydrological cycle to global warming, J. Climate, 19, 5686-5699, 2006.

Hidalgo, H. G., Dettinger, M. D., and Cayan, D. R.: Downscaling with Constructed Analogues: Daily Precipitation and Temperature Fields over the United States, CEC Report CEC-500-2007123, January 2008, 2008.

Huang, M., Hou, Z., Leung, L. R., Ke, Y., Liu, Y., Fang, Z., and Sun, Y.: 2013: Uncertainty Analysis of Runoff Simulations and Parameter Detectability in the Community Land Model - Evidence from MOPEX Basins and Flux Tower Sites, J. Hydrometeorol., doi:10.1175/JHM-D-12-0138.1, in press, 2013.

IPCC: Summary for policymakers, in: Climate Change 2007: the physical science basis. Contribution of working group I to the fourth assessment report of the intergovernmental panel on climate change, edited by: Solomon, S., Qin, D., Manning, M., Chen, Z., Marquis, M., Averyt, K. B., Tignor, M., and Miller, H. L., Cambridge University Press, Cambridge, 2007.
Ke, Y., Leung, L. R., Huang, M., Coleman, A. M., Li, H., and Wigmosta, M. S.: Development of high resolution land surface parameters for the Community Land Model, Geosci. Model Dev., 5, 1341-1362, doi:10.5194/gmd-5-1341-2012, 2012.

Kenny, J. F., Barber, N. L., Hutson, S. S., Linsey, K. S., Lovelace, J. K., and Maupin, M. A.: Estimated use of water in the United States in 2005: US Geological Survey Circular 1344, 52, 2009.

Kim, S. H., Edmonds, J., Lurz, J., Smith, S. J., and Wise, M.: The Object-oriented Energy Climate Technology Systems (ObjECTS) Framework and Hybrid Modeling of Transportation The Energy Journal (Special Issue \#2), 51-80, 2006.

Kimball, J. S., Running, S. W., and Nemani, R. R.: An improved method for estimating surface humidity from daily minimum temperature, Agr. Forest Meteorol., 85, 87-98, 1997.

Konar, M., Hussein, Z., Hanasaki, N., Mauzerall, D. L., and Rodriguez-Iturbe, I.: Virtual water trade flows and savings under climate change, Hydrol. Earth Syst. Sci., 17, 3219-3234, doi:10.5194/hess-17-3219-2013, 2013.

Kraucunas, K., Clarke, L., Dirks, J., Hathaway, J., Hejazi, M., Hibbard, K., Huang, H. , Jin, C., Kintner-Meyer, M., Kleese van Dam, K., Leung, R., Li, H., Moss, R., Peterson, M., Rice, J., Scott, M., Thomson, A., Voisin, N., and West, T.: Investigating the Nexus of Climate, Energy, Water, and Land at Decisionrelevant Scales: The Platform for Regional Integrated Modeling and Analysis (PRIMA), Climatic Change, in review, 2013.

Kyle, P., Davies, E., Dooley, J. J., Smith, S. J., Clarke, L., Edmonds, J., and Hejazi, M. I.: Influence of climate change mitigation technology on global demands of water for electricity generation, Int. J. Greenh. Gas Con., 13, 112-123. doi:10.1016/j.ijggc.2012.12.006, 2013.

Lawrence, D. M., Oleson, K. W., Flanner, M. G., Thornton, P. E., Swenson, S. C., Lawrence, P. J., Zeng, X., Yang, Z.-L., Levis, S., Sakaguchi, K., Bonan, G. B., and Slater, A. G.: Parameterization Improvements and Functional and Structural Advances in Version 4 of the Community Land Model, Journal of Advances in Modeling Earth Systems, 3, 27 pp., 2011.

Lehner, B., R-Liermann, C., Revenga, C., Vörösmarty, C., Fekete, B., Crouzet, P., and Döll, P.: High resolution mapping of the world's reservoirs and dams for sustainable river flow management. Frontiers in Ecology and the Environment. Source: GWSP Digital Water Atlas. Map 81: GRanD Database (V1.0), available online at: http://atlas.gwsp.org, 2008.

Lehner, B., Liermann, C. R., Revenga, C., Vörösmarty, C., Fekete, B., Crouzet, P., Döll, P., Endejan, M., Frenken, K., Magome, J., Nilsson, C., Robertson, J. C., Rödel, R., Sindorf, N., and Wisser, D.: High-resolution mapping of the world's reservoirs and dams for sustainable river-flow management, Front. Ecol. Environ., 9, 494-502, doi:10.1890/100125, 2011.

Leung, L. R., Kuo, Y.-H., and Tribbia, J.: Research Needs and Directions of Regional Climate Modeling Using WRF and CCSM, B. Am. Meteorol. Soc., 87, 1747-1751, 2006.

Li, H., Huang, M., Wigmosta, M., Ke, Y., Coleman, A., Leung, L. R., Wang, A., and Ricciuto, D. M.: Evaluating runoff simulations from the Community Land Model 4.0 using observations from flux towers and a mountainous watershed, J. Geophys. Res., 116, D24120, doi:10.1029/2011JD016276, 2011.

Li, H.-Y., Huang, M., Tesfa, T., Ke, Y., Sun, Y., Liu, Y., and Leung, L. R.: A subbasin-based framework to represent land surface pro- 
cesses in an Earth System Model, Geosci. Model Dev. Discuss., 6, 2699-2730, doi:10.5194/gmdd-6-2699-2013, 2013 a.

Li, H., Wigmosta, M. S., Wu, H., Huang, M., Ke, Y., Coleman, A. M., and Leung, L. R.: A physically based runoff routing model for land surface and earth system models, J. Hydrometeorol., 14, 808-828, doi:10.1175/JHM-D-12-015.1, 2013b.

Liang, X., Lettenmaier, D. P., Wood, E. F., and Burges, S. J.: A Simple hydrologically Based Model of Land Surface Water and Energy Fluxes for GSMs, J. Geophys. Res., 99, 14415-14428, 1994.

Maurer, E. P., Wood, A. W., Adam, J. C., Lettenmaier, D. P., and Nijssen, B.: A long-term hydrologically-based data set of land surface fluxes and states for the conterminous United States, J. Climate, 15, 3237-3251, 2002.

Mishra, M., Cherkauer, K. A., Niyogi, D., Lei, M., Pijanowski, B. C., Ray, D. K., Bowling, L. C., and Yang, G.: A regional scale assessment of land use/land cover and climatic changes on water and energy cycle in the upper Midwest United States Journal, Int. J. Climatol., 30, 2025-2044, doi:10.1002/joc.2095, 2010.

Mitchell, K. E., Lohmann, D., Houser, P. R., Wood, E. F., Schaake, J. C., Robock, A., Cosgrove, B. A., Sheffield, J., Duan, Q., Luo, L., Higgins, R. W., Pinker, R. T., Tarpley, J. D., Lettenmaier, D. P., Marshall, C. H., Entin, J. K., Pan, M., Shi, W., Koren, V., Meng, J., Ramsay, B. H., and Bailey, A. A.: The Multi-institution North American Land Data Assimilation System (NLDAS): Utilizing multiple GCIP products and partners in a continental distributed hydrological modeling system, J. Geophys. Res., 109, D07S90, doi:10.1029/2003JD003823, 2004.

Monfreda, C., Ramankutty, N., and Hertel, T.: Global agricultural land use data for climate change analysis. Economic Analysis of Land Use, in: Global Climate Change Policy, edited by: Hertel, T., Rose, S., and Tol, R., New York, Routledge: 368 pp., 2009.

Neitsch, S. L., Arnold, J. G., Kiniry, J. R., Srinivasan, R., and Williams, J. R.: Soil and Water Assessment Tool Theoretical Documentation, version 2005, edited, Temple, TX: Grassland, Soil and Water Research Laboratory, Agricultural Research Service, 2005.

Pokhrel, Y., Hanasaki, N., Koirala, S., Cho, J., Yeh, P. J.-F., Kim, H., Kanae, S., and Oki, T.: Incorporating Anthropogenic Water Regulation Modules into a Land Surface Model, J. Hydrometeorol., 13, 255-269, doi:10.1175/JHM-D-11-013.1, 2012.

Siebert, S. and Döll, P.: The Global Crop Water Model (GCWM): Documentation and first results for irrigated crops. Frankfurt Hydrology Paper 07, Institute of Physical Geography, University of Frankfurt, Frankfurt am Main, Germany, 2008.

Tamea, S., Allamano, P., Carr, J. A., Claps, P., Laio, F., and Ridolfi, L.: Local and global perspectives on the virtual water trade, Hydrol. Earth Syst. Sci., 17, 1205-1215, doi:10.5194/hess-17-12052013, 2013.
Tesfa, T. K, Leung, L. Y. R., Huang, M., Li, H. , Voisin, N., and Wigmosta, M.S.: Scalability of grid- and subbasin-based land surface modeling approaches for hydrologic simulations. Journal of Geophysical Research - Atmosphere. In revision.2013

Thornton, P. E. and Running, S. W.: An improved algorithm for estimating incident daily solar radiation from measurements of temperature, humidity, and precipitation, Agr. Forest Meteorol., 93, 211-228, 1999.

Thornton, P. E., Hasenauer, H., and White, M. A.: Simultaneous estimation of daily solar radiation and humidity from observed temperature and precipitation: an application over complex terrain in Austria, Agr. Forest Meteorol., 104, 255-271, doi:10.1016/S0168-1923(00)00170-2, 2000.

TVA (Tennessee Valley Authority): Heat and Mass Transfer Between a Water Surface and the Atmosphere, Engineering Laboratory Report No. 14, Norris, TN, USA, 1972.

Vano, J. A., Voisin, N., Cuo, L., Hamlet, A. F., Elsner, M. M., Palmer, R. N., Polebitski, A., and Lettenmaier, D. P.: Climate change impacts on water management in the Puget Sound region, Washington, USA, Climatic Change, 102, 225-260, doi:10.1007/s10584-010-9846-1, 2010a.

Vano, J. A., Scott, M., Voisin, N., Stöckle, C. O., Halmet, A. F., Mickleson, K. E. B., Elsner, M. M., and Lettenmaier, D. P.: Climate change impacts on water management and irrigated agriculture in the Yakima River basin, Washington, USA, Climatic Change, 102, 287-317, doi:10.1007/s10584-010-9856-z, 2010b.

Van Rheenen, N. T., Wood, A. W., Palmer, R. N., and Lettenmaier, D. P.: Potential Implications of PCM Climate Change Scenarios for Sacramento - San Joaquin River Basin Hydrology and Water Resources, Climatic Change, 62, 257-281, January, 2004.

Voisin, N., Li, H., Ward, D., Huang, M., Wigmosta, M., and Leung, L. R.: On an improved sub-regional water resources management representation for integration into earth system models, Hydrol. Earth Syst. Sci., 17, 3605-3622, doi:10.5194/hess-173605-2013, 2013.

Viers, J. H.: Hydropower Relicensing and Climate Change, J. Am. Water Resour. As., 47, 655-661, doi:10.1111/j.17521688.2011.00531.x, 2011.

Wada, Y., van Beek, L. P. H., Viviroli, D., Dürr, H. H., Weingartner, R., and Bierkens, M. F. P.: Global monthly water stress: 2. Water demand and severity of water stress, Water Resour. Res., 47, W07518, doi:10.1029/2010WR009792, 2011.

Wise, M., Calvin, K., Thomson, A., Clarke, L., Bond-Lamberty, B., Sands, R., Smith, S. J., Janetos, A., and Edmonds, J.: Implications of Limiting $\mathrm{CO}_{2}$ Concentrations for Land Use and Energy, Science, 324, 1183-1186, 2009. 